\title{
The correlative triad among aging, dopamine, and cognition: Current status and future prospects
}

\author{
Lars Bäckman ${ }^{\mathrm{a}, \mathrm{b}, *}$, Lars Nyberg ${ }^{\mathrm{c}}$, Ulman Lindenberger ${ }^{\mathrm{b}}$, Shu-Chen Li ${ }^{\mathrm{b}}$, Lars Farde ${ }^{\mathrm{d}}$ \\ ${ }^{a}$ Aging Research Center, Division of Geriatric Epidemiology, Neurotec, Karolinska Institute, Box 6401, S 11382 Stockholm, Sweden \\ ${ }^{\mathrm{b}}$ Max Planck Institute for Human Development, Center for Lifespan Psychology, Berlin, Germany \\ ${ }^{\mathrm{c}}$ Department of Psychology, University of Umea, Sweden \\ ${ }^{\mathrm{d}}$ Department of Clinical Neuroscience, Psychiatry Section, Karolinska Institute, Stockholm, Sweden
}

\begin{abstract}
The brain neuronal systems defined by the neurotransmitter dopamine (DA) have since long a recognized role in the regulation of motor functions. More recently, converging evidence from patient studies, animal research, pharmacological intervention, and molecular genetics indicates that DA is critically implicated also in higher-order cognitive functioning. Many cognitive functions and multiple markers of striatal and extrastriatal DA systems decline across adulthood and aging. Research examining the correlative triad among adult age, DA, and cognition has found strong support for the view that age-related DA losses are associated with age-related cognitive deficits. Future research strategies for examining the DA-cognitive aging link include assessing (a) the generality/specificity of the effects; (b) the relationship between neuromodulation and functional brain activation; and (c) the release of DA during actual task performance. (c) 2006 Elsevier Ltd. All rights reserved.
\end{abstract}

Keywords: Aging; Cognition; Dopamine; Neurotransmission; Presynaptic; Postsynaptic; PET

\section{Contents}

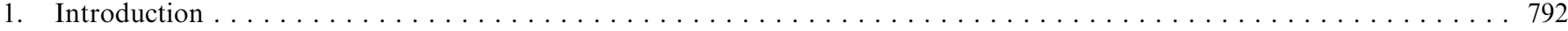

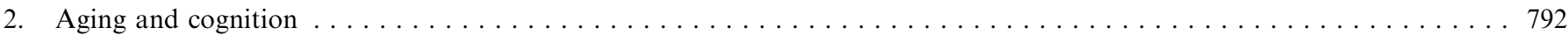

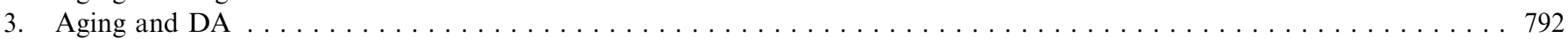

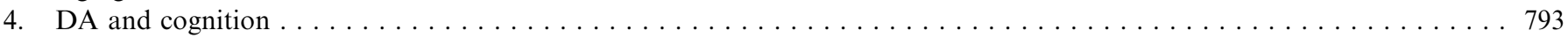

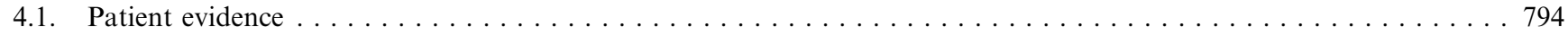

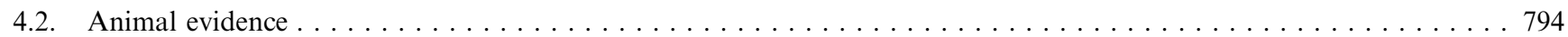

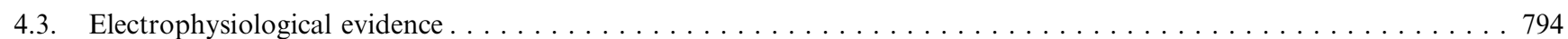

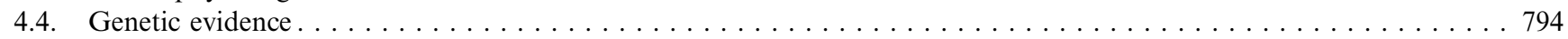

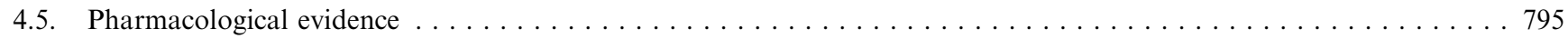

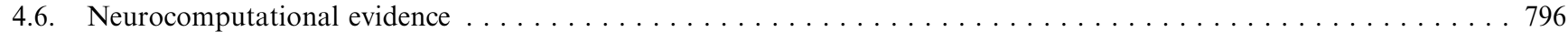

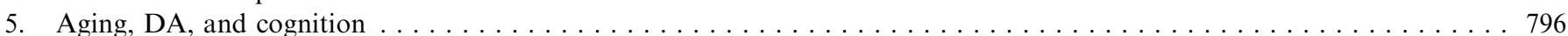

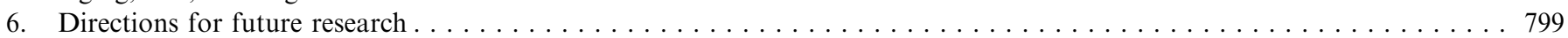

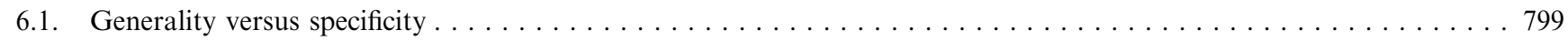

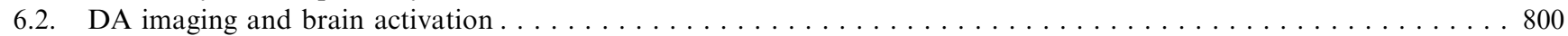

6.3. Pharmacological intervention, COMT genotype, and brain activation $\ldots \ldots \ldots . \ldots \ldots 1$

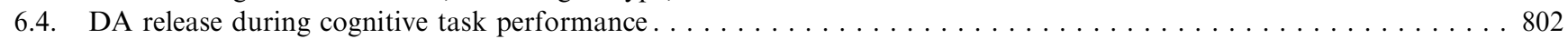

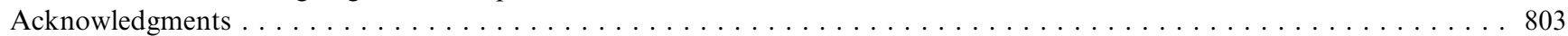

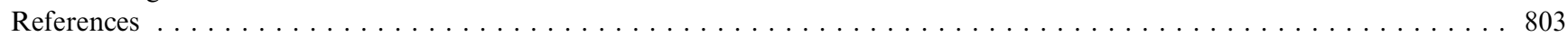

\footnotetext{
*Corresponding author. Aging Research Center, Karolinska Institute, Box 6401, S 11382 Stockholm, Sweden. Tel.: + 46869058 26; fax: +4686905954
}

E-mail address: lars.backman@neurotec.ki.se (L. Bäckman). 


\section{Introduction}

In this article, we review evidence on the relationship of age-related deficits in various cognitive functions to agerelated changes in dopaminergic neurotransmission. The review is organized into five subsections. We begin by briefly outlining some major trends in behavioral research on cognitive aging. We then discuss in some detail in vitro and molecular imaging findings demonstrating strong negative linkages between adult age and different dopamine (DA) markers. Following this, we present converging evidence that DA is critically implicated in multiple cognitive functions. These three sections are synthesized into a review of research on the correlative triad among adult age, DA markers, and cognitive performance. In the final section, we propose several lines of future research that should provide more definite evidence regarding the role of DA in cognitive aging.

\section{Aging and cognition}

Despite substantial individual differences in onset, rate, and scope, there is pervasive evidence that several cognitive functions decline during the course of the normal aging process (see Bäckman et al., 1999, for review). For example, within the domain of memory, tasks assessing the ability to maintain and manipulate information (i.e., working memory) and tasks assessing the ability to consciously recollect information acquired in a certain place at a certain time (i.e., episodic memory), exhibit a marked performance deterioration from early to late adulthood (see Bäckman et al., 2001, for review). Similarly, psychometric tests reflecting fluid aspects of intelligence (e.g., Digit Symbol, Block Design) as well as related experimental tasks tapping, for example, perceptual closure and syllogistic reasoning abilities reveal robust decline across the adult life span (Kausler, 1991; Salthouse, 1992; Lövdén and Lindenberger). Such tests involve relatively unfamiliar materials and require fast and efficient solutions to new problems.

Along with findings from research targeting other cognitive domains demonstrating age-related deficits, such as executive functioning (West, 1996), the pattern of results that is emerging suggests that older adults are especially disadvantaged when fast and efficient processing in novel task situations is required. Although it is debated whether the decline in these cognitive domains normally begins in early (Park, 2000; Park et al., 2002) or middle (Rönnlund et al., 2005) adulthood, most available evidence indicates that the decline process proceeds in a gradual fashion after its onset. Much research is aimed at identifying the neural mechanisms of cognitive decline in adulthood and aging. Such mechanisms can potentially implicate cellular and subcellular changes as well as large-scale changes in the morphology and functional responsiveness of regions and regional networks. In the present paper, we focus specifically on the relationship of age-related deficits in cognitive abilities to age-related losses of biomarkers for the DA system.

To be sure, the focus on DA in the current article does not imply that changes in other neurotransmitters (e.g., noradrenaline, acetylcholine) are unimportant to understanding the biological basis for age-related cognitive deficits. Rather, a long-term goal in the cognitive neuroscience of aging is to delineate how neurotransmitter alterations interact with other brain-based changes (e.g., in gray and white-matter) as well as with genetic and environmental factors in shaping cognitive aging.

\section{Aging and DA}

Much of the work on the relationship between aging and DA neurotransmission has focused on the caudate and the putamen, two major nuclei of the striatal complex having dense dopaminergic innervation. As a result thereof, the conditions for reliable analyses of DA biomarkers in vitro as well as in vivo are very favorable in the striatum. There is strong evidence for age-related losses in pre- and postsynaptic biochemical markers of the nigrostriatal DA system. Most of the relevant studies have investigated postsynaptic DA markers (i.e., $\mathrm{D}_{1}$ and $\mathrm{D}_{2}$ receptor densities). The $D_{1}$ receptor is only expressed in the postsynaptic neuron, whereas the $\mathrm{D}_{2}$ receptor is to a minor extent also expressed in the presynaptic neuron where it serves as an autoreceptor. Autopsy studies indicate losses of both $\mathrm{D}_{1}$ (Cortes et al., 1989; Rinne et al., 1990) and $\mathrm{D}_{2}$ (Seeman et al., 1987; Severson et al., 1982) receptor densities from early to later adulthood, the rate of decline being estimated to just below $10 \%$ per decade. Similar findings for $\mathrm{D}_{1}$ (Suhara et al., 1991; Wang et al., 1998) and $\mathrm{D}_{2}$ (Nordström et al., 1992; Antonini et al., 1993; Ichise et al., 1998) receptor densities have been documented in vivo, using molecular imaging modalities such as positron emission tomography (PET) and single-photon emission computed tomography (SPECT).

In addition, there is evidence for age-related decline in the DA transporter (DAT). The DAT is a commonly used presynaptic marker, because this membrane-bound protein regulates reuptake of DA from the synapse to the presynaptic neuron. As with $\mathrm{D}_{1}$ and $\mathrm{D}_{2}$ binding, postmortem studies (Allard and Marcusson, 1989; Bannon et al., 1992; Bannon and Whitty, 1997; Ma et al., 1999) as well as PET and SPECT work (Van Dyck et al., 1995; Rinne et al., 1998) indicate marked age-related losses of the DAT, the average decrease mimicking that observed for postsynaptic markers.

As noted, the bulk of research on the relationship between aging and DA neurotransmission has focused on striatal DA markers. Studies on extrastriatal DA markers have been hampered by a lack suitable radioligands for imaging of the sparser dopaminergic innervation in extrastriatal brain regions such as the neocortex and the limbic system. However, an early PET study focusing on the relatively abundant $D_{1}$ receptor found comparable 
rates of age-related loss in the striatum and the frontal cortex (Suhara et al., 1991). Post-mortem evidence also demonstrates an age-related decrease of frontal $\mathrm{D}_{1}$ receptor densities (De Keyser et al., 1990). These findings have more recently been extended to the minute densities of extrastriatal $\mathrm{D}_{2}$ receptors, using a high-affinity PET ligand tailored for $\mathrm{D}_{2}$ binding outside the striatum (Kaasinen et al., 2000, 2002; Inoue et al., 2001). The evidence indicates clear age-related losses in $\mathrm{D}_{2}$ binding not only in the frontal cortex, but also in the temporal, parietal, and occipital cortices as well as in hippocampus, amygdala, and thalamus. The magnitude of these age-related effects on extrastriatal DA systems resembles closely those observed for the striatum. Thus, an age-related decrease of DA markers throughout the brain appears to be part of the normal aging process.

Similar to the behavioral literature on cognitive aging, there is some controversy as to whether the age-related DA loss is linear across the adult span. Although most studies have reported evidence for a linear age-DA relationship (see Reeves et al., 2002, for review), an exponential age trajectory with exacerbated loss after middle adulthood has been observed for both $\mathrm{D}_{2}$ receptor densities (Rinne et al., 1990; Antonini et al., 1993) and DAT binding potential (Bannon and Whitty, 1997; Ma et al., 1999). Obviously, the latter trajectory concurs with observations of a later onset of age-related cognitive decline (Rönnlund et al., 2005). Although the reasons for the discrepant findings remain unclear, it should be noted that most relevant studies involve relatively few subjects, and several studies may not have covered a sufficiently wide age range. Conceivably, these factors underlie the different function forms relating age to DA markers in the extant literature.

The age-related loss of DA markers may have multiple loci at a neuronal or molecular level. First, there is an agerelated reduction of DA cell bodies in substantia nigra, with an average loss around 3\% per decade (Fearnley and Lees, 1991). In a unique study, post-mortem cell counts in the substantia nigra were highly related to an ante-mortem imaging marker for DA synthesis capacity (Snow et al., 1993). This suggests that neuronal number influences the total synthesis rate of DA. Second, there is a reduction of synapses that progresses from childhood through adulthood to old age, which may reflect both adaptive, plastic processes during development and predominantly non-adaptive loss in late life (Gopnic et al., 1999). Third, there is evidence suggesting an age-related decrease in the number of biomarker proteins per cell. Specifically, work with rodents has demonstrated substantial agerelated losses in steady-state levels and synthesis of $\mathrm{D}_{2}$ receptor messenger ribonucleic acid (mRNA; Mesco et al., 1993). Relatedly, human work shows that the age-related decrease in DAT mRNA may exceed the extent of neuronal loss (Seeman et al., 1987; Severson et al., 1982; De Keyser et al., 1990). Thus, the bottom line is that age-related alterations in neuronal number, synapses, and protein concentrations may all contribute to the general down regulation of the DA system with advancing adult age.

With regard to putative causative factors for this down regulation, it has been proposed that common mechanisms may regulate both pre- and postsynaptic maturation of the DA systems during neurodevelopment, and that an age-related decrease in the functional demands on dopaminergic pathways may occur during adulthood (Bäckman and Farde, 2004). Further, it has been suggested that age-related DA losses may reflect failure to cope with oxidative stress and subsequent cell damage (Joseph et al., 1996). Supportive evidence for this notion comes from animal research indicating a relationship among striatal DA levels, markers of oxidative damage, and motor function (CardozoPelaez et al., 1999). It has also been suggested that the expression of DA itself may contribute to degenerative processes through the production of neurotoxins by autooxidation (Fornstedt et al., 1990; Luo and Roth, 2000).

Irrespective of the specific mechanism implicated, it is important to note that the age-related downward trajectories are remarkably similar for pre- and postsynaptic DA markers (Severson et al., 1982; Wang et al., 1998; Nordström et al., 1992; Antonini et al., 1993; Ichise et al., 1998; Van Dyck et al., 1995; Rinne et al., 1998). Consistent with these parallel patterns, Volkow et al. (1998a) found a sizable relationship between $D_{2}$ receptor binding and DAT binding in the striatum. Importantly, this association remained after partialing out chronological age. This suggests that the expression of receptors and transporters may reflect adaptation of major components of the dopaminergic pathways. Although the causality remains unclear, one interesting possibility is provided in work on DAT knock-out mice, showing a reduction of $\mathrm{D}_{2}$ receptor mRNA in postsynaptic medium-spiny neurons (Gainetdinov et al., 1999). Given that loss of DAT may initially result in increased DA concentrations (Shinkai et al., 1997), it is conceivable that increased DA levels lead to an adaptive down regulation of DA-mediated neurotransmission in postsynaptic neurons, corresponding to postsynaptic losses of DA receptors with advancing age (Sakata et al., 1992; Zhang et al., 1995).

\section{DA and cognition}

Dopaminergic neurotransmission has since long been identified as having a central role in efficient motor functioning (Freed and Yamamoto, 1985; McEntee et al., 1987). However, several more recent lines of evidence (from patient, animal, electrophysiological, genetic, pharmacological, and neurocomputational studies) suggest that DA is also critically implicated in many higher-order cognitive abilities. This evidence is reviewed next. 


\subsection{Patient evidence}

Studies on clinical populations with known pathophysiology of the DA system, such as patients with Huntington's disease (HD) and Parkinson's disease (PD), indicate deficits across multiple cognitive domains including executive functions, visuospatial skill, episodic memory, verbal fluency, perceptual speed, and reasoning (Brandt and Butters, 1986; Brown and Marsden, 1990). Note that these patterns of impairment resemble closely those observed in aging (Prull et al., 1999). Further, PET studies have demonstrated a sizable relationship of $\mathrm{D}_{1}$ and $\mathrm{D}_{2}$ receptor binding as well as DAT binding to performance in the aforementioned task domains in groups of mildly to moderately ill HD patients (Bäckman et al., 1997; Lawrence et al., 1998). In PD, a similarly strong relationship between PET-derived presynaptic measures of the synthesis rate of $\left[{ }^{18} \mathrm{~F}\right] \mathrm{DOPA}$ as well of DAT density to measures of episodic memory and executive functioning has been documented (Holthoff et al., 1994; Müller et al., 2000; Bruck et al., 2005).

\subsection{Animal evidence}

There is substantial evidence from animal studies that lesioning of dopaminergic pathways results in cognitive deficits. For example, local destructions of dopaminergic nerve terminals at different sites (e.g., septum, nucleus accumbens, prefrontal cortex) produce impairment across multiple cognitive domains in rodents and monkeys alike, including memory (Simon et al., 1986), inhibitory functions (Jones and Robbins, 1992), set-shifting (Roberts et al., 1994), and spatial attention (Boussaoud and Kermadi, 1997). In a similar vein, lesioning of dopaminergic pathways at the level of the subthalamic nucleus, which deprives the input from nigral DA cells to projection areas, results in deficits in tasks assessing attentional as well as executive functioning and motor sequencing (Baunez et al., 1995; Baunez and Robbins, 1999). More recently, studies with mutant mice have demonstrated that absence of $\mathrm{D}_{2}$ receptors is associated with decreased number of prefrontal neurons and impaired performance in tasks assessing spatial working memory and perceptual discrimination (Glickstein et al., 2002, 2005). Thus, data from lesion studies and molecular genetics indicate an important role of DA in regulating performance across a variety of cognitive domains.

\subsection{Electrophysiological evidence}

Dynamic, context-dependent temporal binding of cellassembly codes through synchronous oscillations is assumed to function as a mechanism by which relations between currently perceived object features or regenerated representations of stored experiences are held active in working memory (von der Malsburg, 1985; Singer and Gray, 1995). DA neuromodulation plays a critical role in this form of binding by synchronizing prefrontal oscillatory activity (Seamans and Yang, 2004). Specifically, DA activation of GABA neurons phase-locks the activity of interneurons, changing their temporal firing pattern but not their rate (de Charms and Merzenich, 1996). When temporal binding is perceptually driven, deficient DA neuromodulation is expected to result in impaired stimulus-induced phase resetting of ongoing oscillatory activity. In agreement with this prediction, Winterer et al. (2004) observed greater spectral response variability ("prefrontal broadband noise") of evoked electrophysiological responses in individuals with lower working memory performance as well as in individuals with genetic risk for schizophrenia. This line of evidence is highly relevant to cognitive aging research, as aging-related increases in within-person processing variability have been observed across a variety of cognitive and motor tasks (MacDonald et al., 2003; Li et al., 2004).

\subsection{Genetic evidence}

Genetic polymorphisms provide new leads in research on the functional role of genes expressed in brain. A common approach is to relate allelic variants to functional measures at a biochemical or behavioral level. One example is provided in recent research on cognitive correlates of allelic variants in the gene coding for Catechol $O$-methyltransferase (COMT). Driven initially by research examining the DA hypothesis of schizophrenia, this work has also provided support for the role of DA systems in cognitive functioning.

The COMT enzyme inactivates extracellular DA by conversion to 3-methoxythyramine (Weinshilboum et al., 1999). The role of COMT in regulating DA levels appears to be particularly dominant in the prefrontal cortex (Gogos et al., 1998; Karoum et al., 1994). A common polymorphism (Val108/158Met) in the COMT gene has been associated with most of the human variation in enzyme activity (Mannisto and Kaakkola, 1999). Of chief importance, the enzymatic activity is three to four times as high for the Val than for the Met variant at normal body temperatures (Lotta et al., 1995). The alleles are codominant with heterozygous persons (Val/Met) having intermediate enzyme activity between homozygotic persons (i.e. Val/Val > Val/Met > Met/Met; Weinshilboum et al., 1999). Conceivably, as a result of the allelic differences in enzymatic activity, Val carriers have less DA activity in the prefrontal cortex as compared to Met carriers (Egan et al., 2001).

Basic evidence of an influence of COMT on cognition comes from studies on COMT knock-out mice (Kneavel et al., 2000) as well as from animal (Liljequist et al., 1997) and human (Gasparini et al., 1997) research demonstrating performance enhancement from COMT inhibitors in working-memory tasks. Cognitive studies comparing the different allelic variants indicate an advantage of Met over Val carriers in executive functioning (i.e., fewer 
perseverative errors in the Wisconsin Card Sorting Test; Egan et al., 2001; Joober et al., 2002; Malhotra et al., 2002; Mattay et al., 2003) as well as in tasks assessing processing speed and attention (Bilder et al., 2002). Some of these studies on young and middle-aged adults involve patients with schizophrenia, others involve normal subjects, and still others have a mixture of patients and controls. In general, the results are similar for the different subject groups. These findings have recently been extended to children and older adults. Diamond et al. (2004) showed a selective superiority in 10-year old Met/Met children for a task taxing working memory and inhibitory functions; no genotype group differences were seen in a working memory task with low inhibitory demands, or in episodic recall and mental rotation tasks. A similar Met/Met advantage in middle-aged, young-old and old-old adults was reported by De Frias and colleagues for episodic and semantic memory (de Frias et al., 2004) as well as for executive functioning and visuospatial skill (de Frias et al., 2005).

Although there may be differential sensitivity of COMT genotype to different cognitive domains within individual studies, the pattern of results emerging across studies is one of a rather broad influence on performance in many different kinds of cognitive tests. A final point to note is that some studies (de Charms and Merzenich, 1996) suggest a dose-response effect of genotype on cognitive performance (i.e., Met/Met $>\mathrm{Val} / \mathrm{Met}>\mathrm{Val} / \mathrm{Val}$ ), others (Lotta et al., 1995; Egan et al., 2001) suggest that the major effect lies between homozygotic Met carriers and the other genotype groups, and still others (Karoum et al., 1994) show that the most pronounced difference is between the homozygotic Val carriers and the other groups. Differences across studies in statistical power to detect effects between specific genotype groups may account for the discrepant findings.

\subsection{Pharmacological evidence}

There is evidence from both animals and humans that pharmacological manipulations of DA transmission may be related to cognitive performance. Administration of Damphetamine (D-AMP) elevates the synaptic concentration of DA and may serve as a model for DA hyperactivity. Several studies have reported D-AMP-related performance gains in tasks assessing information-processing speed (Halliday et al., 1994), discrimination (Kelly et al., 1991), and vigilance (Spiegel, 1978). In a series of studies, Luciana et al. (1992, 1998) and Luciana and Collins (1997) found that bromocriptine, a $\mathrm{D}_{2}$ receptor agonist, facilitates delayed spatial working-memory performance in healthy volunteers. The pattern of findings in these studies suggests that the effects were not secondary to changes in basic sensorimotor, attentional, or global arousal processes. Rather, they seemed to reflect changes in the temporal integration of a sensory cue and the requested response.

Conversely, Luciana and Collins (1997) demonstrated that administration of haloperidol, a $\mathrm{D}_{2}$ receptor antago- nist, worsened performance in a working-memory task in which performance gains from a $\mathrm{D}_{2}$ agonist (bromocriptine) were observed. In a related study, it was found that a rather low dose of haloperidol impaired performance in tasks assessing psychomotor speed and working memory (Ramaekers et al., 1999). Likewise, research with monkeys (Sawaguchi and Goldman-Rakic, 1991) indicates that DA receptor antagonists cause reversible impairment in motor and cognitive tasks.

However, there are inconsistencies in the extant pharmacological literature. Inconsistent observations may depend on pharmacological characteristics of the test compound, doses, endogenous DA levels, and pre-experimental cognitive skill. Luciana and Collins (1997) reported a facilitative effect of bromocriptine on spatial working memory at lower doses, but not at the same doses as initially reported by the same research team (Luciana et al., 1992). Kimberg et al. (1997) found that persons with low working-memory capacity showed positive bromocriptinerelated effects on working-memory performance, whereas those with high working-memory capacity showed negative effects (see also Mehta et al., 2000). By contrast, Kimberg and D'Esposito (2003) documented larger effects of pergolide, a non-selective agonist for both the $\mathrm{D}_{1}$ and the $\mathrm{D}_{2}$ receptor subtypes, on delayed working-memory performance for persons with greater working-memory capacity than for those with lower capacity.

Although the reasons for the mixed findings remain unclear, they may reflect interactions between subjectrelated and drug-related factors that vary between receptor subtypes. Interestingly, similar inconsistencies have been observed at a neurophysiological level. There is evidence of an inverted U-shaped dose-response function with administration of DA agonists in monkeys (Cai and Arnsten, 1997). Such observations are particularly common for partial agonists, which may act as antagonists if the intrinsic activity is lower than the physiological activity, and as agonists if the intrinsic activity is higher.

In a recent pharmacogenomic imaging study on brain activation during working memory ( $n$-back) performance, Mattay et al. (2003) obtained evidence of direct relevance to the inverted $\mathrm{U}$-shaped function hypothesized to characterize the relationship of DA signaling to cognitive functioning. The key finding was a triple interaction among COMT genotype, D-AMP, and cognitive demand. In line with the notion that DA levels (and demand-induced shift in DA levels) are affected by all three factors (Met/ Met $>\mathrm{Val} / \mathrm{Val}$; drug $>$ placebo; higher cognitive demand (3-back) > lower cognitive demand (2-back), the Val/Val carriers showed a more efficient left prefrontal response under the influence of D-AMP when $n$-back conditions were most demanding. By contrast, the Met/Met carriers exhibited worse performance and a less efficient prefrontal response under these conditions. This pattern is entirely consistent with the U-shaped DA-brain/cognition relationship. Specifically, administration of D-AMP and increasing cognitive demands should move the Val/Val carriers from a 


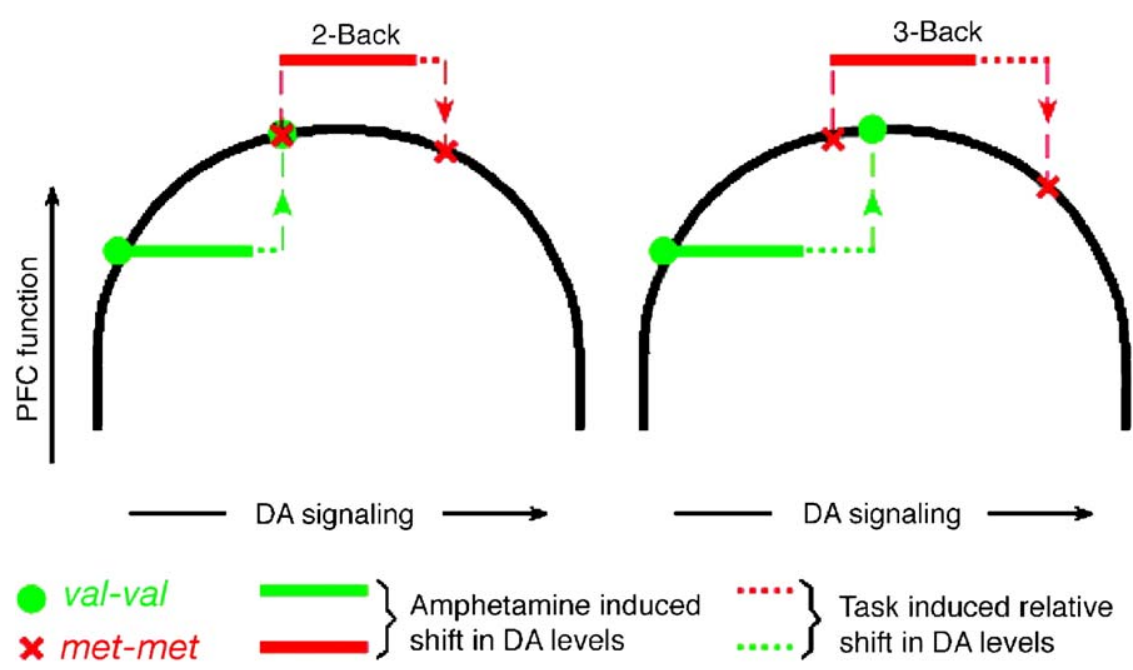

Fig. 1. Theoretical inverted-U model describing the effects of COMT genotype, working-memory load, and D-AMP on prefrontal DA signaling and function. The model has three simplified assumptions: (a) fixed baseline positions for each genotype based on differential COMT activity; (b) greater demand of DA release with increasing working-memory load; and (c) a fixed pharmacological effect of D-AMP on increasing synaptic DA levels. Adapted from Mattay et al. (2003).

lower-than-optimal toward an optimal DA level. By contrast, given that the Met/Met carriers are closer to an optimal DA level under baseline conditions, the experimentally induced DA increases may have shifted their DA level to the decline portion of the inverted U function. A schematic representation of these relationships is portrayed in Fig. 1.

\subsection{Neurocomputational evidence}

Some of the empirical observations discussed in this chapter have been integrated into neurocomputational models. In these models, DA is commonly hypothesized to facilitate the responsivity of neural networks in activity transmission both within and between neural networks (Oades, 1985). By enhancing the neural signal relative to background noise (Sawaguchi et al., 1988), DA is assumed to promote the firing frequency of innervated neurons (Daniel et al., 1991).

Servan-Schreiber et al. (1998a) proposed a model specifically developed to accomodate the effects of DAMP on selective attention. In this model, DA effects are simulated as a change in the gain parameter of the activation function of neural assemblies in the area of release. Interestingly, effects on motor performance are thought to result from gains over the response layer, resulting in increased speed, but impaired accuracy. By contrast, effects on attention are simulated as a change in gains over the attention layer, resulting in improved speed and accuracy, particularly under demanding conditions. Results from a study investigating the effects of D-AMP on motor and cognitive performance in a selective-attention task were in excellent agreement with the proposed model (Servan-Schreiber et al., 1998b).

Of particular consequence to the current article, Li et al. (2001) modified the Servan-Schreiber et al. (1998a) model, in order to link age-related cognitive deficits to deficient dopaminergic modulation. Age-related decline in dopaminergic modulation was simulated by randomly sampling values for the gain parameter of the activation function from a distribution with a lower mean at every processing step. Reducing the mean of the stochastic gain parameter leads to reduced neuronal responsivity, which, in turn, increases neural noise and results in less distinctive activation patterns. These less distinctive activation patterns are hypothesized to be a key determinant of cognitive aging. The model also accounts for the inverted U-shaped dose-performance function by demonstrating that, at extremely low or high levels of gain (corresponding to low versus excessive DA levels), neuronal activity in response to different inputs saturates, resulting in less discriminative activation patterns (see Fig. 2) and poorer cognitive performance (Li and Sikström, 2002).

\section{Aging, DA, and cognition}

Given that (a) adult age is negatively related to cognitive performance and the density of DA markers; and (b) DA markers are positively related to cognitive performance, a logical next step is to relate all these variables that form a correlative triad. Although few studies hitherto have examined the relationship of age-related DA changes to age-related cognitive changes, the pattern of findings is strikingly consistent, and supportive of an important role of DA systems in cognitive aging. A common feature of these studies is that they involve adult life-span samples with a rectangular age distribution from early to late adulthood.

Using PET, Wang and collaborators (Wang et al., 1998) found strong relationships among age, striatal $\mathrm{D}_{1}$ receptor binding, and performance in a psychomotor test. Similar results were obtained in a recent SPECT study examining 

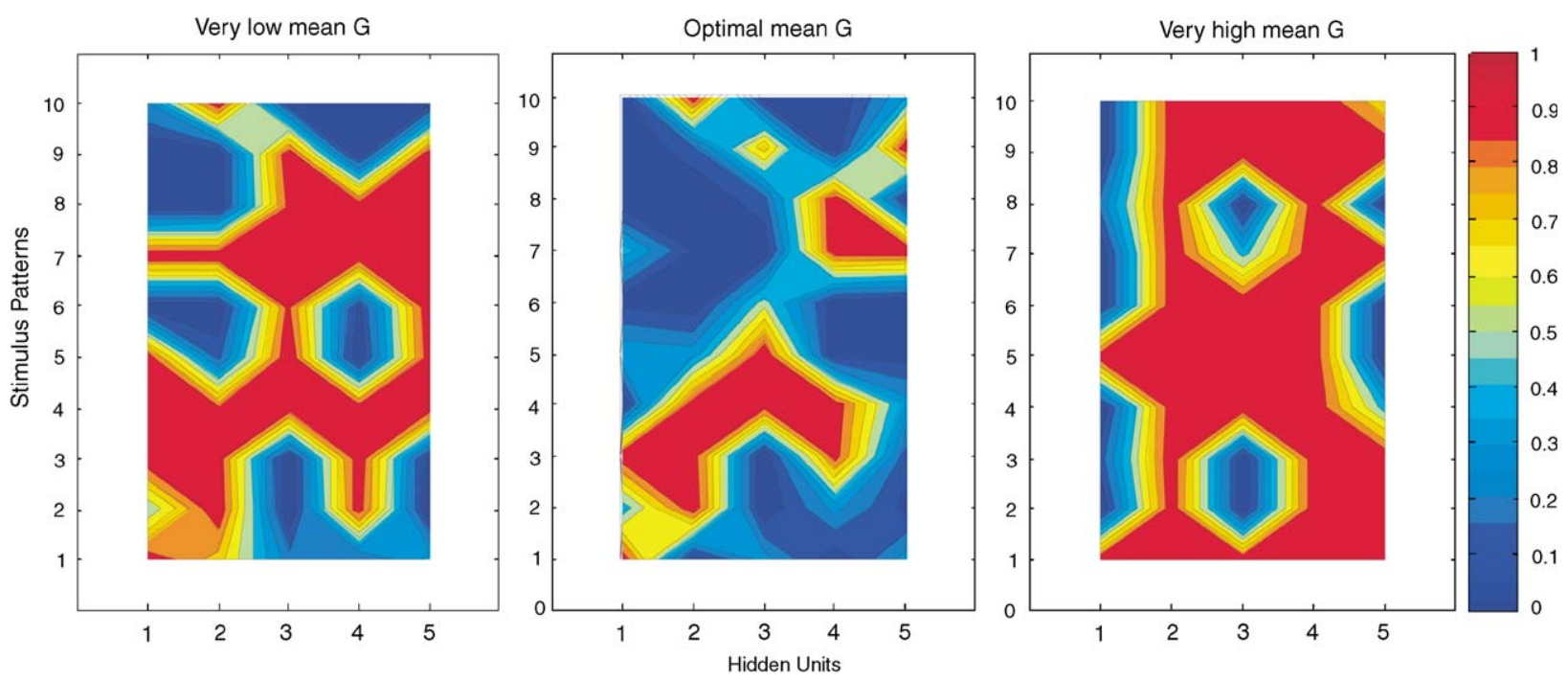

Fig. 2. Connectionist models simulate the inverted U-shape relation between dopaminergic neuromodulation and task performance. The three panels display activation patterns of five different processing units ( $x$-axes) at the hidden layer of a connectionist network in response to 10 different stimulus patterns ( $y$-axes), corresponding to 10 items in a memory-span task. Differences in dopaminergic neuromodulation are simulated by varying the mean of the stochastic gain parameter $(G)$ of the sigmoid activation function relating input to output activation in the network's processing units. Output activations of hidden units vary from 0 (blue) to 1 (red). At intermediate levels of $G$ (middle panel), activation patterns differ more across stimulus patterns than at very low (left panel) and very high (right panel) $G$ levels. Thus, memory span is longer for networks with intermediate compared to very low or very high G levels. Adapted from Li and Sikström (2002).

the association among age, striatal $\mathrm{D}_{2}$ receptor binding, and finger tapping performance (Yang et al., 2003). Although these studies reported bivariate correlations only, the results are important in that they document the correlative triad within specific samples.

In another PET study (Volkow et al., 1998b), striatal $\mathrm{D}_{2}$ binding was assessed in conjunction with testing of executive and motor functioning as well as perceptual speed; all these domains are known to be sensitive to both aging and pathological conditions associated with striatal dysfunction. In line with earlier studies, $\mathrm{D}_{2}$ receptor binding decreased with advancing age and there were negative relationships between age and performance in the cognitive tests. The most interesting finding was that partial correlations revealed moderate to strong relationships of $\mathrm{D}_{2}$ binding to motor and cognitive performance also after controlling for chronological age. These results indicate that age-related decreases in DA function are related to deficits in both cognitive and motor functioning, and suggest that DA activity may influence performance irrespective of age.

These findings were corroborated in a related PET study (Bäckman et al., 2000), which examined striatal $\mathrm{D}_{2}$ binding and cognitive performance using a somewhat different task constellation. Here, two age-sensitive cognitive domains were targeted: episodic memory and perceptual speed. As expected, increasing age was negatively associated with performance in the episodic memory and speed tasks, and there was a marked decrease in striatal $\mathrm{D}_{2}$ binding across age. The key finding was that statistical control of $\mathrm{D}_{2}$ binding effectively eliminated the influence of age on cognitive performance, whereas $\mathrm{D}_{2}$ binding contributed to
Table 1

Amount of variance $\left(R^{2}\right)$ in cognitive performance accounted for by age and dopamine $\mathrm{D}_{2}$ receptor binding as a function of order of entry

\begin{tabular}{llllll}
\hline & \multicolumn{2}{l}{ Perceptual speed } & & \multicolumn{2}{l}{ Episodic memory } \\
\cline { 2 - 3 } \cline { 5 - 6 } & Dots & Trail making & & Word recognition & Face recognition \\
\hline Age & .52 & .34 & .13 & .27 \\
$\mathrm{D}_{2}$ & .11 & .22 & .27 & .24 \\
Total & .63 & .56 & .40 & .51 \\
$\mathrm{D}_{2}$ & .61 & .55 & .38 & .48 \\
Age & .02 & .01 & .02 & .03 \\
Total & .63 & .56 & .40 & .51 \\
\hline
\end{tabular}

Adapted from Bäckman et al. (2000).

the cognitive variation independent of age (see Table 1). These results provide further evidence for the view that DA is implicated in age-related cognitive deficits as well as in cognitive functioning in general.

In the studies reviewed above, postsynaptic DA markers were assessed. It has been suggested that DAT density - a marker of the presynaptic neuron - is more sensitive than postsynaptic receptor densities as an indicator of the activity of the dopaminergic system (Mozley et al., 1999). Specifically, because DAT indirectly regulates the occupancy of DA on $\mathrm{D}_{1}$ and $\mathrm{D}_{2}$ receptor-containing neurons, this protein may serve as a more general marker of the DA system. In a SPECT study, Mozley et al. (2001) reported age-related reductions of the DAT in the striatum along with age-related deficits in verbal episodic memory. Importantly, DAT binding in the striatum was strongly 


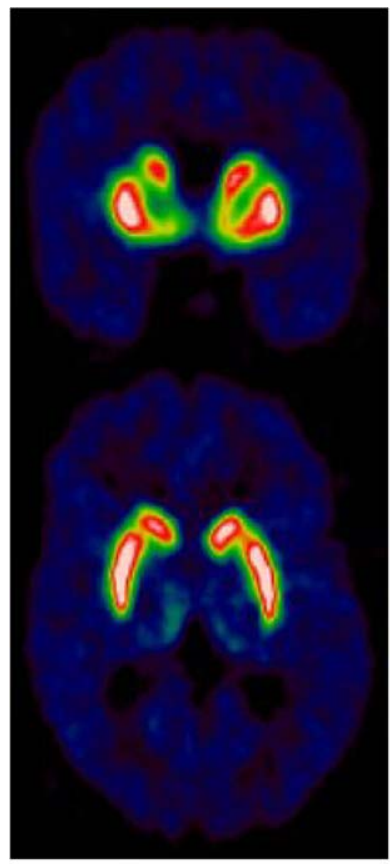

Age 34 (Male)

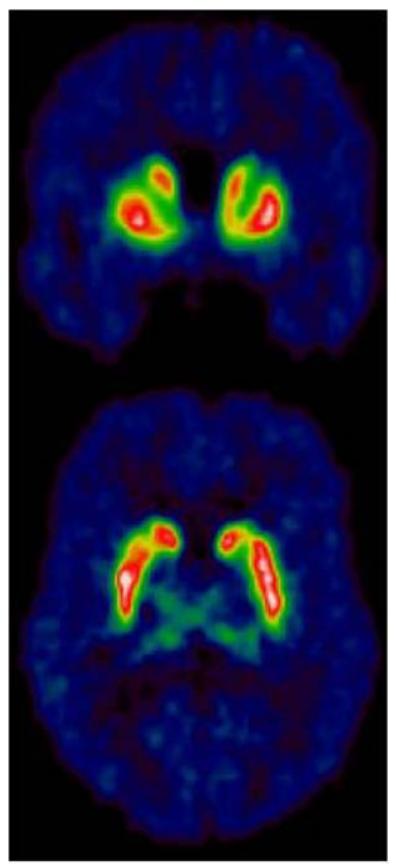

Age 50 (Male)

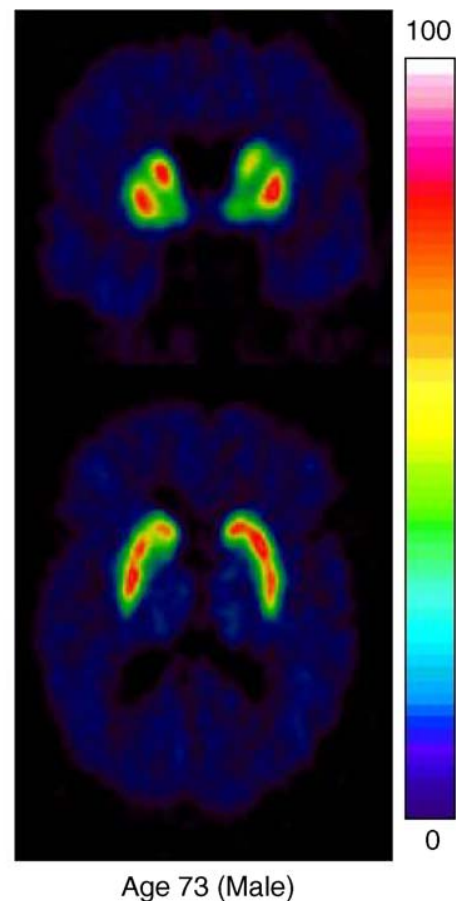

Age 73 (Male)

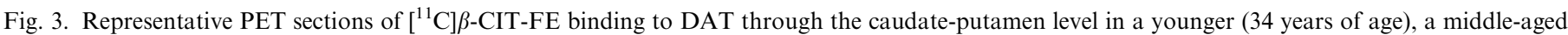

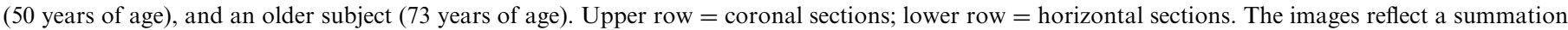
of radioactivity from 9 to $63 \mathrm{~min}$ after injection of $\left[{ }^{11} \mathrm{C}\right] \beta$-CIT-FE. Adapted from Erixon-Lindroth et al. (2005).

Table 2

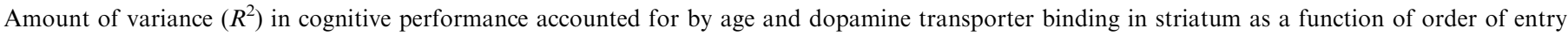

\begin{tabular}{|c|c|c|c|c|c|c|}
\hline & \multicolumn{3}{|c|}{ Episodic memory } & \multicolumn{2}{|c|}{ Executive function } & \multirow[t]{2}{*}{ Crystallized IQ Information } \\
\hline & Word recall & Figure recall & Face recognition & WM & Word fluency & \\
\hline Age & .31 & .35 & .28 & .40 & .15 & .07 \\
\hline DAT & .24 & .19 & .13 & .13 & .16 & .28 \\
\hline Total & .55 & .55 & .41 & .53 & .31 & .35 \\
\hline DAT & .46 & .49 & .40 & .49 & .30 & .31 \\
\hline Age & .09 & .06 & .01 & .04 & .01 & .04 \\
\hline Total & .55 & .55 & .41 & .53 & .31 & .35 \\
\hline
\end{tabular}

Note. $\mathrm{DAT}=$ dopamine transporter; $\mathrm{WM}=$ working memory; $\mathrm{IQ}=$ intelligence.

Adapted from Erixon-Lindroth et al. (2005).

associated with memory performance in both younger and older adults.

An age-related decrease of DAT density in caudate and putamen was also documented in a recent PET study on DA and cognitive aging (Erixon-Lindroth et al., 2005; see Fig. 3). Further, there were age-related deficits in tests of episodic memory, working memory, and word fluency, but not in a test of general knowledge. Similar to a related study on $\mathrm{D}_{2}$ binding (Yang et al., 2003), the agerelated cognitive deficits were completely mediated by DAT density, although DAT density contributed to the performance variation in memory and fluency over and above age. The latter finding was substantiated by the result that DAT density also was related to performance variability in the age-insensitive knowledge test (see Table 2).

Thus, the available evidence suggests that pre- and postsynaptic markers of the nigrostriatal DA system are powerful mediators of the cognitive changes that occur across adulthood and old age, as well as strong general correlates of cognitive performance. Regarding the apparent similarity in the patterns of age differences for pre- and postsynaptic DA markers, it may be noted that Volkow et al. (1998a) reported a strong association between the densities of DAT and $\mathrm{D}_{2}$ receptors across adulthood. The DAT $-\mathrm{D}_{2}$ association was age-independent, suggesting that common genetic or adaptive mechanisms may regulate the expression of DA receptors and transporters irrespective of 
age. Support for a genetic regulation of DA markers has been provided in research demonstrating an association between polymorphisms of the $\mathrm{D}_{2}$ gene and the density of $\mathrm{D}_{2}$ receptors (Jönsson et al., 1999). Thus, changes in preand postsynaptic DA function may be an interdependent and generalized phenomenon in human aging (Morgan and Finch, 1998).

Although the available data on aging, DA, and cognition are strikingly consistent and biologically plausible, there are important issues that remain unclear. In the next and final section, we outline several future research directions on the influence of DA on cognitive aging that seek to address these issues.

\section{Directions for future research}

The research reviewed above clearly indicates that the overall efficacy of the dompaminergic system declines during the normal aging process, and that impairment of DA modulation at the neuronal and molecular level may be associated with a variety of age-related cognitive deficits. With new lines of evidence emerging from animal, genetic, pharmacological, and brain imaging studies, future research that combines insights from these domains of inquiry may help bringing research on aging, neuromodulation, and cognition to a new level of integration.

\subsection{Generality versus specificity}

An interesting observation in the studies conducted on DA and cognitive aging is the similarity of the effects of different DA markers. As is true with corresponding research on patients with HD (Bäckman et al., 1997; Lawrence et al., 1998), markers of $\mathrm{D}_{1}, \mathrm{D}_{2}$, and DAT binding in both the caudate and the putamen show strong relationships to each other as well as to cognitive performance (Wang et al., 1998; Yang et al., 2003; Volkow et al., 1998b; Bäckman et al., 2000; Mozley et al., 2001; Erixon-Lindroth et al., 2005).

These general patterns are observed despite postulated functional differences between the striatal structures. The caudate and the putamen receive DA input from the substantia nigra in the brain stem, but are part of different, albeit parallel, topographic frontostriatal circuits (Alexander and Crutcher, 1990; Parent and Hazrati, 1995). Traditionally, the caudate circuits are thought to be particularly relevant to complex cognitive functioning, whereas the putaminal circuits are primarily implicated in motor activity (Alexander et al., 1986; Bhatia and Marsden, 1994; Houk et al., 1995).

Biochemically, the $\mathrm{D}_{1}$ and $\mathrm{D}_{2}$ subtypes show preferential localization to distinct striatal pathways. Although a proportion of the $D_{1}$ and $D_{2}$ receptors are co-localized on the same neurons, $\mathrm{D}_{1}$ receptors are mainly expressed in neurons in the "direct" striatonigral feedback pathway, whereas $\mathrm{D}_{2}$ receptors are expressed in "indirect" pathways that include interneurons (Gerfen et al., 1995; Hersch et al.,
1995). At a histological level, this differential organization corresponds to the observation that $\mathrm{D}_{1}$ neurons are primarily located in striosomes, whereas $\mathrm{D}_{2}$ neurons are preferentially found in the matrix component of the striatum (Joyce et al., 1986; Graybiel et al., 1994).

Further, direct injections of either $\mathrm{D}_{1}$ or $\mathrm{D}_{2}$ receptor agonists into the prefrontal cortex have been found to facilitate working-memory performance in monkeys (Williams and Goldman-Rakic, 1995). However, whereas the effects of the $D_{1}$ agonist were specific in modulating memory fields of locally active neurons, the $\mathrm{D}_{2}$-related effects were more general, likely reflecting changes in the integration of motor, memory, and motivational capacities. More recently, a double dissociation between $D_{1}$ and $D_{2}$ receptors within an oculomotor working memory task was demonstrated in monkeys. Specifically, $\mathrm{D}_{2}$ receptors modulated memory-guided saccades in the task, whereas $D_{1}$ receptors modulated persistent memory-related activity (Wang et al., 2004).

The similar effects of different DA markers on agerelated cognitive deficits may appear counterintuitive in view of these apparent differences at cellular or neurocircuitry levels as well as with regard to specific functional correlates. However, as should be obvious from the current review, relatively few age-comparative imaging studies have addressed the DA-cognition relationship, and the relevant studies are characterized by relatively small sample sizes. Thus, the general failure to obtain differential relationships among brain regions as well as different biochemical markers may reflect the limited nature of the database along with low statistical power in individual studies. Future research using larger samples, multiple radioligands for distinct DA markers, and suitable approaches for parametric receptor imaging (Cselenyi et al., 2002) should provide more conclusive evidence concerning the extent to which the effects of DA markers decreases on cognitive aging are global or can be attributed to specific markers in specific brain structures.

For example, is it possible to conceive of a functional dissociation in humans between $\mathrm{D}_{1}$ and $\mathrm{D}_{2}$ receptors similar to that demonstrated for working memory in monkeys (Wang et al., 2004). A key issue here concerns the fact that the monkey work is based on acute pharmacological challenges, whereas the available human studies deal with interindividual variability over several decades. Obviously, the possibility for adaptive regulatory mechanisms is greater in the latter case. A further concern is whether the available measurement devices (i.e., PET) are sensitive enough to detect potential differences between DA markers regarding their role in cognitive functioning?

In addition, could it be that DA losses in a particular brain area (e.g., striatum) are more critical than DA losses in other areas (e.g., frontal cortex) for certain domains of cognitive functioning (e.g., psychomotor speed), whereas the opposite pattern holds for other cognitive domains (e.g., working memory)? Indeed, single-cell recordings in monkeys suggest differential roles for the striatum (i.e., 
rapid, specific, latency-related) and the frontal cortex (i.e., slow, flexible, accuracy-related) during conditional association learning (Pasupathy and Miller, 2005). Alternatively, considering the integrated network of striatal and extrastriatal brain regions (Alexander et al., 1986; Graybiel, 2000), and given that pre- and postsynaptic DA markers appear to exhibit similar decline with age (Bäckman and Farde, 2004; Parent and Hazrati, 1995) throughout the human brain (Wang et al., 1998; Nordström et al., 1992; Kaasinen et al., 2000, 2002; Inoue et al., 2001), selective effects may not be expected. This issue could be addressed by comparing the extent to which striatal DA markers versus extrastriatal DA markers account for age-related deficits across different cognitive tasks.

\subsection{DA imaging and brain activation}

Another avenue for future research concerns the relationship between age-related changes in neuromodulation and age-related changes in task-induced brain activity. By collecting PET-based DA data and functional-imaging data during task performance on the same individuals, several intriguing issues in the cognitive neuroscience of aging could be addressed. For example, in activation studies, an under-recruitment of task-relevant frontal regions has been associated with age-related deficits in tasks assessing working memory (Rypma and D'Esposito, 2000; Rypma et al., 2001) and episodic memory (Grady et al., 1995; Stebbins et al., 2002). In this context, it is of interest to note that several studies on DA and cognitive aging have used cognitively demanding tasks (e.g., execu- tive tasks, episodic memory tasks) that have been shown to activate prefrontal regions in functional imaging studies (see Cabeza and Nyberg, 2000, for review). Thus, it is tempting to relate changes in DA neurotransmission to changes in task-related brain activity (as reflected by regional blood flow), such that impaired neurotransmission underlies decreased activation. Studies in which imaging of the DA system is combined with functional imaging during cognitive task performance have not yet been performed. However, a promising observation regarding the biomarker-brain physiology link is that a strong age-independent relationship has been reported between striatal $\mathrm{D}_{2}$ binding and frontal and cingulate resting-state glucose metabolism (Volkow et al., 2000; see Fig. 4).

In addition, in some task situations (e.g., episodic retrieval) older adults may exhibit relatively higher activity increases than younger adults in specific brain regions (e.g., left prefrontal cortex). Such findings have been interpreted to reflect reallocation of neural resources in old age that serves compensatory purposes. On this view, increased activity in the older person is assumed to be associated with better cognitive performance (Cabeza, 2002; Cabeza et al., 2002). However, it has also been proposed that greater regional activity of older adults may reflect lack of specificity of neural processing that may, in part, stem from deficits in inhibitory intercallosal processes (Bäckman and Farde, 2004; Li et al., 2001). By the latter view, increased recruitment of brain regions is thought to be associated with impaired neurotransmission, particularly in systems having a modulatory role such as the DA system. These theoretical alternatives can be evaluated by means of
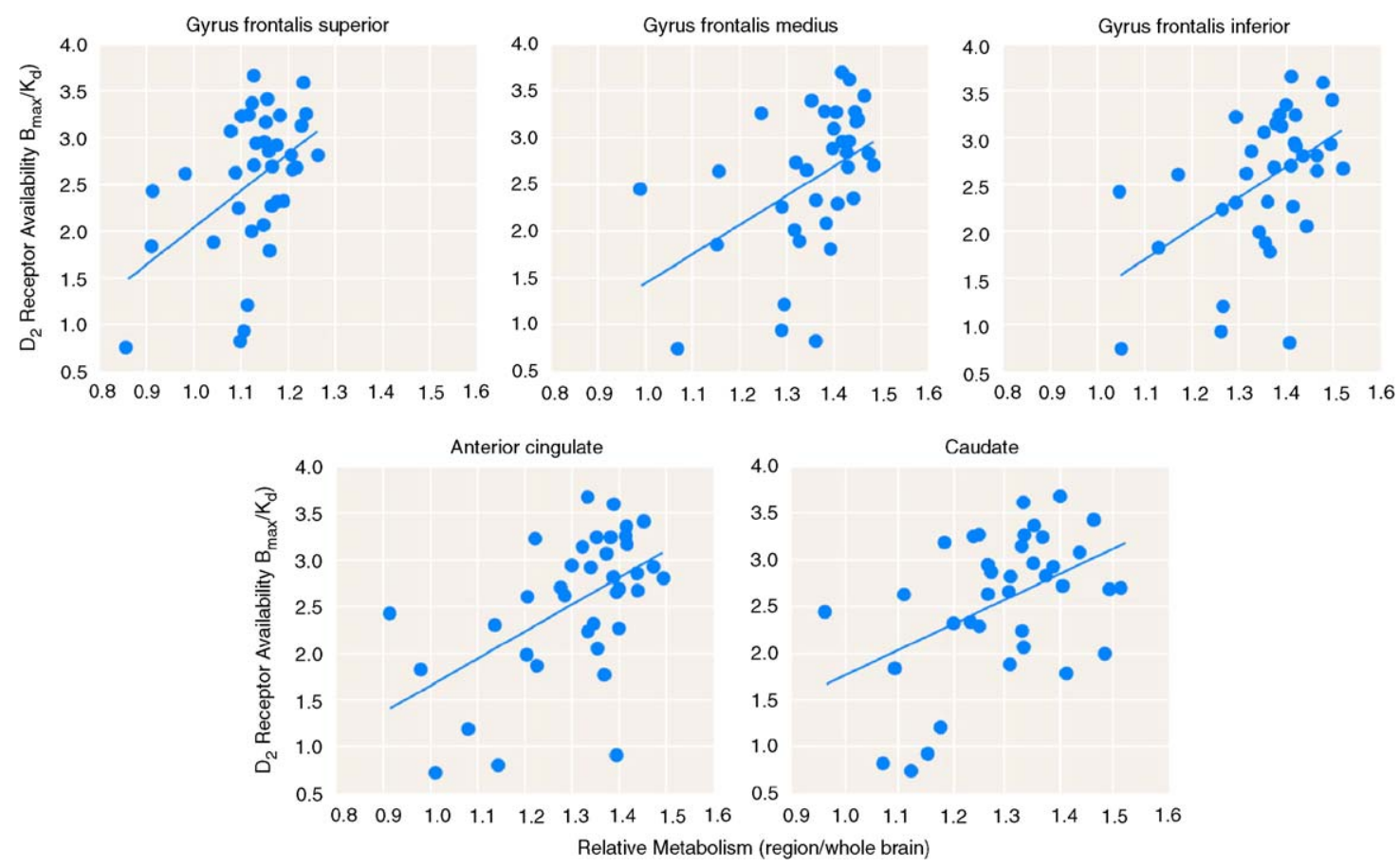

Fig. 4. Regression slopes depicting correlations between striatal dopamine $\mathrm{D}_{2}$ receptors $\left(B_{\max } / K_{\mathrm{d}}\right)$ and relative glucose metabolism in preselcetd brain regions in 37 healthy subjects $24-86$ years of age. Adapted from Volkow et al. (2000). 
multi-modal imaging, relating data on DA markers and regional blood flow to cognitive performance in young and older adults.

Relations of blood flow and task performance to EEG/ MEG signals also may help to disambiguate the functional status of age-related changes in prefrontal activity. Empirical evidence (Seamans and Yang, 2004; Winterer et al., 2004) and computational models (Breakspear et al., 2003; Li et al., 2005) suggest that DA neuromodulation is critically involved in synchronization of oscillatory activity, which in turn is assumed to serve as a mechanism by which perceived or stored features are bound and held active in working memory. Changes in cerebral blood flow predominantly reflect postsynaptic processes (Logothetis et al., 2001), and animal models suggest a close link between single-neuron spike rhythms and postsynaptically generated field potentials (Engel and Fries P Singer, 2001). Also, (Lauritzen, 2001) observed random spike-firing patterns of Purkinje cells under baseline conditions, but rhythmic oscillations and increased cerebral blood flow after electric stimulation, with the spike rate remaining unchanged.

Thus, to the extent that loss of synchronicity of oscillatory activity reflects aging losses in DA neuromodulation, age-based deficits in tasks that impose high working-memory or executive demands should be associated with: (a) decreased responsivity of DA release during performance; (b) noisier neuronal signaling due to impaired phase resetting of oscillatory activity (Winterer et al., 2004); and (c) less focused and less pronounced increase in hemodynamic activity. Simultaneous or separate assessments of these indicators within the same sample of aging individuals have not yet been undertaken but seem highly desirable. With respect to EEG/MEG indicators of oscillatory activity, we recommend to complement traditional ERP analyses by methods that provide more direct indications of the amount of task-relevant phase resetting of ongoing oscillatory activity (Makeig et al., 2004; Gruber et al., 2005).

Of further interest is that the magnitude of activation in the dorsolateral prefrontal cortex (DLPFC) is related to level of performance in the $n$-back task, such that it peaks at 2-back and is reduced at 3-back (Callicott et al., 1999). This pattern of neural response was found to mirror working-memory performance, suggesting a link between DLPFC activity and working-memory capacity. Further support for this notion comes from findings that trainingrelated increases in working-memory capacity correlate with increased activity in the DLPFC (Olesen et al., 2004). To the extent that DLPFC activity relates to workingmemory capacity and such activity is modifiable by training, an interesting future research question is whether training-related improvements of cognitive performance in older adults is related to post-training increases in DLPFC activity, and to increasing coherence of oscillatory activity. In turn, if such increases in activity are observed, a critical issue is how they relate to DA neuromodulation. That is, does increased activity in DLPFC correspond to enhanced
DA signaling? Similar questions are relevant in the context of pharmacological intervention, an issue to which we turn next.

\subsection{Pharmacological intervention, COMT genotype, and brain activation}

A supplementary line of research involves manipulation of DA neurotransmission through administration of dopaminergic agonists or antagonists. As noted, it is known that DA agonists may enhance performance (Servan-Schreiber et al., 1998b), whereas DA antagonists may impair performance (Ramaekers et al., 1999) across a variety of cognitive tasks. Further, in support of the inverted U-shaped DA-neurocognition curve (Cai and Arnsten, 1997; Li and Sikström, 2002), the effects of DA on cognition and brain activity seem to be modified by COMT genotype, such that Val carriers (low endogenous levels) show a more efficient frontal response, whereas Met carriers (high endogenous levels) show a less efficient frontal response following administration of a DA agonist (Mattay et al., 2003). These findings open up for a series of interesting research questions regarding the role of DA in cognitive aging.

First, it would be of interest to examine whether DA antagonists, in addition to lowering performance, would lead to a pattern of brain activation during cognitive performance (e.g., working memory, episodic memory) in young adults that resembles that typically exhibited by older adults under placebo conditions (e.g., less specific and more diffuse frontal activation). Simulating cognitive aging in younger adults by means of experimental manipulations (e.g., division of attention) has been a successful approach in behavioral studies (Mäntylä and Bäckman, 1992; Castel and Craik, 2003). The pharmacological approach proposed here would extend this research strategy to the neural level, and provide more mechanistic evidence pertaining to the role of DA neurotransmission in the age-differential patterns of brain activation often observed in functionalimaging studies (Rypma and D'Esposito, 2000; Rypma et al., 2001; Grady et al., 1995; Stebbins et al., 2002; Cabeza, 2002; Cabeza et al., 2002).

Conversely, we may ask whether a DA agonist would alter the brain activation patterns of older people in the opposite direction (i.e., more specific, less diffuse, and associated with better performance). This research issue may profit from considering COMT-related differences in DA signaling. Specifically, by crossing adult age with COMT genotype, four groups of chief interest could be obtained: old-Val/Val (lowest DA levels), old-Met/Met and young-Val/Val (intermediate DA levels), and young-Met/ Met (highest DA levels). On the basis of the inverted Ushaped relationship between DA levels and cognitive/brain function (Mattay et al., 2003; Cai and Arnsten, 1997; Li and Sikström, 2002), older Val/Val carriers may be expected to exhibit the largest cognitive improvement and the most pronounced increase in neural efficiency from a 
DA agonist. Young Val/Val carriers and older Met/ Met carriers may also show some drug-related improvement, whereas young Met/Met carriers may instead deteriorate, because their initially high DA signaling in conjunction with a DA agonist may lead to suboptimally high DA levels. Such an outcome would provide additional experimental evidence on the influence of DA on cognitive aging, as well as on brain and cognitive functioning in general.

Indeed, a recent study examining the effects of pharmacological treatment on spatial-working memory performance in young and old monkeys provides experimental data of direct relevance to this line of reasoning (Castner and Goldman-Rakic, 2004). In this study, old monkeys showed marked increments in delayed spatial-working memory performance following administration of a selective $\mathrm{D}_{1}$ agonist. By contrast, young monkeys showed null effects or performance decrements under the same conditions, a pattern entirely consistent with the inverted U-shaped model. Perhaps most intriguingly, these effects were sustained for more than 1 year after the termination of drug treatment. The long-term maintenance of DA-induced gains in the old monkeys may reflect fundamental alterations in parts of the neural circuitry that underlies spatial-working memory functioning. Thus, the research idea outlined above would not only extend these findings to humans, but also provide novel information on how the influence on age on responsiveness to dopaminergic treatment may be influenced by genetic factors.

\subsection{DA release during cognitive task performance}

Still another potentially interesting research direction focuses on release of DA during actual task performance. In an often-cited PET study, Koepp et al. (1998) demonstrated striatal DA release during performance of a war-type video game under rewarding conditions, as indicated by less radioligand binding to $\mathrm{D}_{2}$ receptors because of task-induced occupancy by endogenous DA. Furthermore, degree of occupancy was related to videogame performance. Striatal DA release was also reported in a cognitively challenging number-comparison task including both verbal and monetary reward (Pappata et al., 2002). Given the central role of the DA system in reward mechanisms (see Schultz, 2002, for review), the extent to which the above findings of DA release reflect the cognitive demands as opposed to the reward properties of the tasks remains unclear.

However, DA release has also been documented during performance of unrewarded motor tasks. Ouchi et al. (2002) reported striatal DA release in PD patients and controls during unilateral foot exercises (i.e., foot extension, flexion movement). In a similarly mundane task, to oppose the thumb and different fingers depending on which digit appeared on a screen, striatal DA release relative to control conditions was also observed (Badgaiyan et al.,
2003). Thus, although the reward component may contribute to DA release during task performance, it appears that it cannot fully account for this phenomenon.

This conclusion is substantiated by research assessing DA release in the amygdala during working memory, episodic memory, and reading (Fried et al., 2001). In this study, microdialysis was used to sample extracellular DA during cognitive performance in a group of pharmacologically resistant epilepsy patients that had electrodes implanted intracranially. The results showed DA release during performance in all cognitive tasks, the effect being larger for memory than for reading. In addition, the degree of DA release in the amygdala was related to performance in the episodic memory task. These findings indicate that task-related DA release can be demonstrated also in brain regions outside the striatal complex. Additional support for this point comes from a recent study examining extrastriatal DA release during vigilance (0-back) and workingmemory (2-back) performance, using a high-affinity $\mathrm{D}_{2}$ tracer (Aalto et al., 2005). The findings showed DA release in the anterior cingulate during both cognitive conditions relative to baseline. In addition, selective DA release was observed in the inferior frontal cortex and the medialtemporal lobe during working-memory performance (see Fig. 5).

Building on these observations, it would be of considerable interest to examine potential age-related differences in DA release during cognitive performance. To the extent that age-related DA changes imply a less dynamic neurotransmitter system, we may expect diminished DA release during performance in older compared to younger adults along with lower task performance. Such findings, indicating age-related reductions in what might be referred to as neurochemical plasticity, would provide on-line evidence of the impact of age-related neuromodulatory deficits on cognitive functioning. In the context of cognitive aging, this approach represents an important advance beyond resting-state DA studies. As noted above, agerelated cognitive deficits are especially pronounced in tasks that require active (executive) stimulus processing (Bäckman et al., 1999, 2001; Kausler, 1991; Salthouse, 1992; Lövdén and Lindenberger; West, 1996). We also reviewed evidence that DA markers are strongly related to performance on executively demanding tasks (Volkow et al., 1998b; Bäckman et al., 2000; Erixon-Lindroth et al., 2005). Along these lines, a DA account of cognitive aging holds that an important reason for the large agerelated differences observed in executively demanding tasks is that such tasks require excessive DA release to be successfully performed (Mattay et al., 2003). As a result, in contrast to less demanding tasks, age-related DA losses should be particularly detrimental. The successful application of this functional molecular-imaging approach to cognitive aging will rest on sensitive methods to detect DA release (Aston et al., 2000; Alpert et al., 2003) as well as on careful selection of taxing, but yet highly motivating cognitive tasks. 

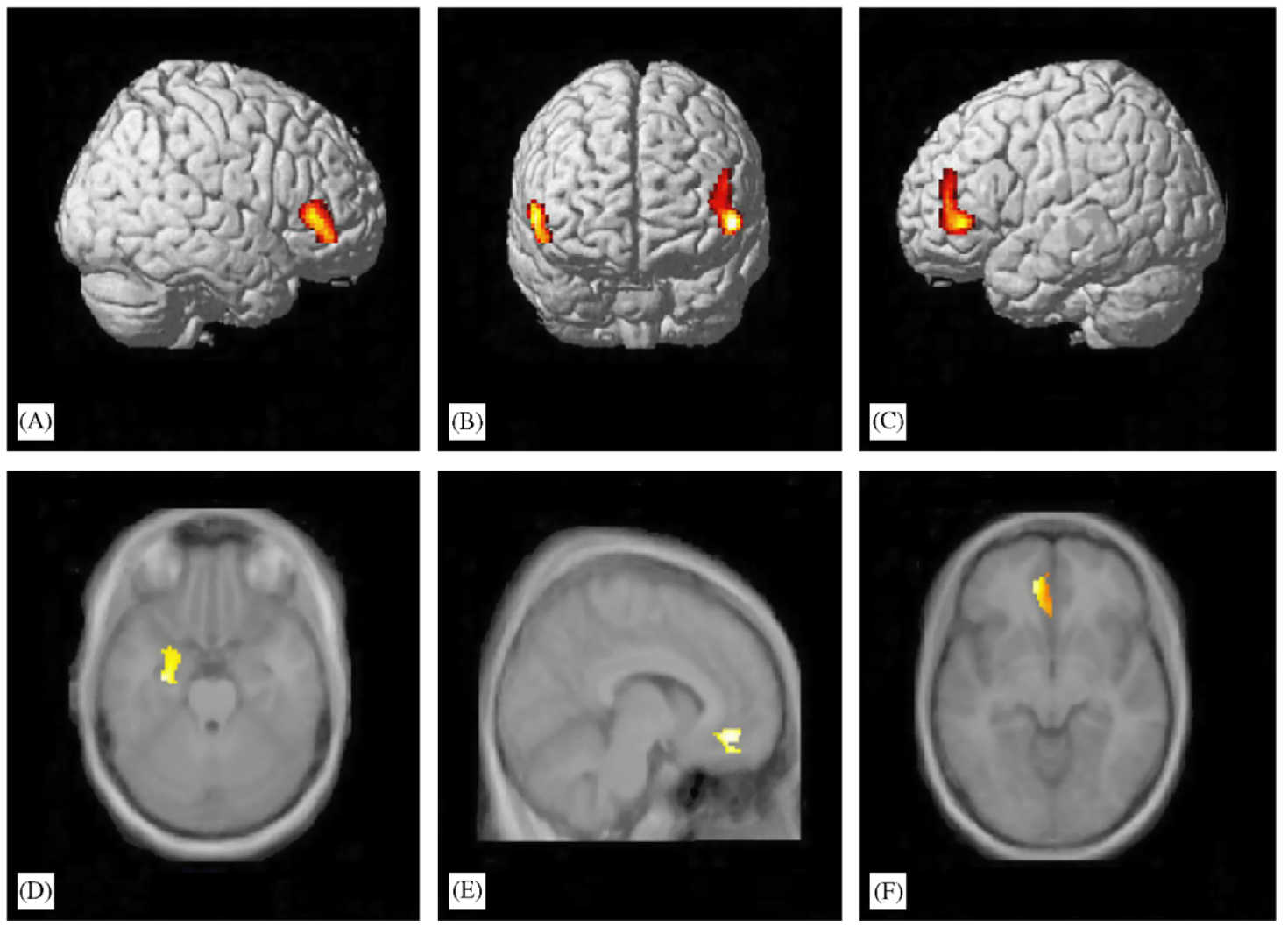

Fig. 5. Visualization of a voxel-based statistical analysis. In comparison to the vigilance task, the binding potential (BP) of $\left[{ }^{11} \mathrm{C}\right] \mathrm{FLB} 457 \mathrm{decreased}$ during the working-memory task bilaterally in the ventrolateral frontal cortex (panels A-C) and in the left medial-temporal lobe (panel D). Compared to restingstate baseline, both the vigilance (panel E) and the working-memory task (panel F) induced a decrease in the BP of $\left[{ }^{11} \mathrm{C}\right] \mathrm{FLB} 457$ in the left ventral anterior cingulate gyrus. The results are visualized on a brain model (upper panels) and on an average MRI template image (lower panels). Adapted from Aalto et al. (2005).

\section{Acknowledgments}

Preparation of this chapter was supported by grants from the Swedish Research Council and the Bank of Sweden Tercentenary Foundation to Lars Bäckman, from the Swedish Research Council to Lars Nyberg and Lars Farde, and from the German Research Association to ShuChen Li and Ulman Lindenberger.

\section{References}

Aalto, S., Brück, A., Laine, M., Någren, K., Rinne, J.O., 2005. Frontal and temporal dopamine release during working memory and attention tasks in healthy humans: a PET study using high-affinity dopamine $\mathrm{D}_{2}$ receptor ligand $\left[{ }^{11} \mathrm{C}\right]$ FLB 457 . Journal of Neuroscience 25, 2471-2477.

Alexander, G.E., Crutcher, M.D., 1990. Functional architecture of basal ganglia circuits: neural substrates of parallel processing. TINS 13, 266-271.

Alexander, G.E., DeLong, M.R., Strick, P.L., 1986. Parallel organization of functionally segregated circuits linking basal ganglia and cortex. Annual Review of Neuroscience 9, 357-381.

Allard, P., Marcusson, J., 1989. Age-correlated loss of dopamine uptake sites labeled with [3H]GBR-12935 in human putamen. Neurobiology of Aging 10, 661-664.

Alpert, N.M., Badgaiyan, R.D., Livni, E., Fischman, A.J., 2003. A novel method for invasive detection of neuromodulatory changes in specific neurotransmitter systems. Neuroimage 19, 1049-1060.
Antonini, A., Leenders, K.L., Reist, H., Thomann, R., Beer, H.F., Locher, J., 1993. Effect of age on $\mathrm{D}_{2}$ dopamine receptors in normal human brain measured by positron emission tomography and $\left[{ }^{11} \mathrm{C}\right]$ raclopride. Archives of Neurology 50, 474-480.

Aston, J.A.D., Gunn, R.N., Worsley, K.J., Ma, Y., Evans, A.C., Dagher, A., 2000. A statistical method for the analysis of positron emission tomography neuroreceptor ligand data. Neuroimage 12, 245-256.

Bäckman, L., Farde, L., 2004. The role of dopamine functions in cognitive aging. In: Cabeza, R., Nyberg, L., Park, D.C. (Eds.), Cognitive Neuroscience of Aging: Linking Cognitive and Cerebral Aging. Oxford University Press, New York, pp. 58-84.

Bäckman, L., Robins Wahlin, T.B., Lundin, A., Ginovart, N., Farde, L., 1997. Cognitive deficits in Huntington's disease are predicted by dopaminergic PET markers and brain volumes. Brain 120, 2207-2217.

Bäckman, L., Small, B.J., Wahlin, Å., Larsson, M., 1999. Cognitive functioning in very old age. In: Craik, F.I.M., Salthouse, T.A. (Eds.), Handbook of Aging and Cognition, vol. 2. Erlbaum, Mahwah, NJ, pp. 499-558.

Bäckman, L., Ginovart, N., Dixon, R.A., Robins Wahlin, T.B., Wahlin, Å., Halldin, C., Farde, L., 2000. Age-related cognitive deficits mediated by changes in the striatal dopamine system. American Journal of Psychiatry 157, 635-637.

Bäckman, L., Small, B.J., Wahlin, Å., 2001. Aging and memory: cognitive and biological perspectives. In: Birren, J.E., Schaie, K.W. (Eds.), Handbook of the Psychology of Aging, vol. 5. Academic Press, San Diego, pp. 349-377.

Badgaiyan, R.D., Fischman, A.J., Alpert, N.M., 2003. Striatal dopamine release during unrewarded motor task in human volunteers. Neuroreport $14,1412-1424$. 
Bannon, M.J., Whitty, C.J., 1997. Age-related and regional differences in dopamine mRNA expression in human midbrain. Neurology 48, 969-977.

Bannon, M.J., Poosch, M.S., Xia, Y., Goebel, D.J., Cassin, B., Kapatos, G., 1992. Dopamine transporter mRNA content in human substantia nigra decreases precipitously with age. Proceedings of the National Academy of Sciences of the United States of America 89, 7095-7099.

Baunez, C., Robbins, T.W., 1999. Effects of dopamine depletion of the dorsal striatum and further interaction with subthalamic nucleus lesions in an attentional task in the rat. Neuroscience 92, 1343-1356.

Baunez, C., Nieoullon, A., Amalric, M., 1995. Dopamine and complex sensorimotor integration: further studies in a conditioned motor task in the rat. Neuroscience 65, 375-384.

Bhatia, K.P., Marsden, C.D., 1994. The behavioral and motor consequences of focal lesions of the basal ganglia in man. Brain 117, 859-876.

Bilder, R.M., Volavka, J., Czobor, P., Malhotra, A.K., Kennedy, J.L., Ni, X., Goldman, R.S., Hoptman, M.J., Sheitman, B., Lindenmayer, J.P., Citrome, L., McEvoy, J.P., Kunz, M., Chakos, M., Cooper, T.B., Lieberman, J.A., 2002. Neurocognitive correlates of the COMT $\mathrm{Val}^{158} \mathrm{Met}$ polymorphism in chronic schizophrenia. Biological Psychiatry $52,701-707$.

Boussaoud, D., Kermadi, I., 1997. The primate striatum: neuronal activity in relation to spatial attention versus motor preparation. European Journal of Neuroscience 9, 2152-2162.

Brandt, J., Butters, N., 1986. The neuropsychology of Huntington's disease. Trends in Neurosciences 9, 118-120.

Breakspear, M., Terry, J.R., Friston, K.J., 2003. Modulation of excitatory synaptic coupling facilitates synchronization and complex dynamics in a nonlinear model of neuronal dynamics. Neurocomputing 52-54, $151-158$.

Brown, R.G., Marsden, C.D., 1990. Cognitive function in Parkinson's disease: from description to theory. Trends in Neurosciences 13, 21-29.

Bruck, A., Aalto, S., Nurmi, E., Bergman, J., Rinne, J.O., 2005. Cortical 6-[F18]fluoro- $L$-dopa uptake and frontal cognitive functions in early Parkinson's disease. Neurobiology of Aging 26, 891-898.

Cabeza, R., 2002. Hemispheric asymmetry reduction in older adults: the HAROLD model. Issue Series Title: Psychology and Aging 17, 85-100.

Cabeza, R., Nyberg, L., 2000. Imaging cognition II: an empirical review of 275 PET and fMRI studies. Journal of Cognitive Neuroscience 12, $1-47$.

Cabeza, R., Anderson, N.D., Locantore, J.K., McIntosh, A.R., 2002. Aging gracefully: compensatory brain activity in high-performing older adults. Neuroimage 17, 1394-1402.

Cai, J.X., Arnsten, A.F., 1997. Dose-dependent effects of the dopamine receptor agonists A77636 and SKF81297 on spatial working memory in aged monkeys. Journal of Pharmacology and Experimental Therapeutics 283, 183-189.

Callicott, J.M., Mattay, V.S., Bertolino, A., Finn, K., Coppola, R., Frank, J.A., Goldberg, T.E., Weinberger, D.R., 1999. Physiological characteristics of capacity constraints in working memory as revealed by functional MRI. Cerebral Cortex 9, 20-26.

Cardozo-Pelaez, F., Song, S., Parthasarathy, A., Hazzi, C., Naidu, K., Sanchez-Ramoz, J., 1999. Oxidative damage in the aging mouse brain. Movement Disorders 14, 972-980.

Castel, A.D., Craik, F.I.M., 2003. The effects of aging and divided attention on memory for item and associative information. Psychology and Aging 18, 873-885.

Castner, S.A., Goldman-Rakic, P.S., 2004. Enhancement of working memory in aged monkeys by a sensitizing regimen of dopamine $D_{1}$ receptor stimulation. Journal of Neuroscience 24, 1446-1450.

Cortes, R., Gueye, B., Pazos, A., Palacios, J.M., 1989. Dopamine receptors in human brain: autoradiographic distribution of $D_{1}$ sites. Neuroscience 28, 262-273.

Cselenyi, Z., Olsson, H., Farde, L., Gulyas, B., 2002. Wavelet-aided parametric mapping of cerebral dopamine $\mathrm{D}_{2}$ receptors using the highaffinity ligand $\left[{ }^{11}\right.$ C]FLB 457 . Neuroimage 17, 47-60.
Daniel, D.G., Weinberger, D.R., Jones, D.W., Zigun, J.R., Coppola, R., Handel, S., Bigelow, L.B., Goldberg, T.E., Berman, K.F., Kleinman, J.E., 1991. The effect of amphetamine on regional cerebral blood flow during cognitive activation in schizophrenia. Journal of Neuroscience 11, 1907-1917.

de Charms, R.C., Merzenich, M.M., 1996. Primary cortical representation of sounds by the co-ordination of action-potential timing. Nature 381, 610-613.

de Frias, C.M., Annerbrink, K., Westberg, L., Eriksson, E., Adolfsson, R., Nilsson, L.G., 2004. COMT gene polymorphism is associated with declarative memory in adulthood and old age. Behavior Genetics 34, 533-539.

de Frias, C.M., Annerbrink, K., Westberg, L., Eriksson, E., Adolfsson, R., Nilsson, L.G., 2005. Catechol $O$-methyltransferase Val ${ }^{158} \mathrm{Met}$ polymorphism is associated with cognitive performance in nondemented adults. Journal Cognitive Neuroscience 17, 1018-1025.

De Keyser, J., De Backer, J.P., Vauquelin, G., Ebinger, G., 1990. The effect of aging on the $\mathrm{D}_{1}$ dopamine receptors in human frontal cortex. Brain Research 528, 308-310.

Diamond, A., Briand, L., Fossella, J., Gehlbach, L., 2004. Genetic and neurochemical modulation of prefrontal cognitive functions in children. American Journal of Psychiatry 161, 125-132.

Egan, M.F., Goldberg, T.E., Kolachana, B.S., Callicott, J.H., Mazzanti, C.M., Straub, R.E., Goldman, D., Weinberger, D.R., 2001. Effect of COMT Val108/158Met genotype on frontal lobe function and risk for schizophrenia. Proceedings of the National Academy of Sciences of the United States of America 98, 6917-6922.

Engel, A.K., Fries P Singer, W., 2001. Dynamic predictions: oscillations and synchrony in top-down processing. Nature Review Neuroscience 2, 704-716.

Erixon-Lindroth, N., Farde, L., Robins Wahlin, T.B., Sovago, J., Halldin, C., Bäckman, L., 2005. The role of the striatal dopamine transporter in cognitive aging. Psychiatry Research Neuroimaging 138, 1-12.

Fearnley, J.M., Lees, A.J., 1991. Aging and Parkinson's disease: substantia nigra regional selectivity. Brain 114, 2283-2301.

Fornstedt, B., Pileblad, E., Carlsson, A., 1990. In vivo autooxidation of dopamine in guinea pig striatum increases with age. Journal of Neurochemistry 55, 655-659.

Freed, C.R., Yamamoto, B.K., 1985. Regional brain dopamine metabolism: a marker for the speed, direction, and posture of moving animals. Science 229, 62-65.

Fried, I., Wilson, C.L., Morrow, J.W., Cameron, K.A., Behnke, E.D., Ackerson, L.C., Maidment, N.T., 2001. Increased dopamine release in the human amygdala during performance of cognitive tasks. Nature Neuroscience 4, 201-206.

Gainetdinov, R.R., Jones, S.R., Caron, M.G., 1999. Functional hyperdopaminerga in dopamine transporter knock-out mice. Biological Psychiatry 46, 303-311.

Gasparini, M., Fabrizio, E., Bonifati, E., Meco, G., 1997. Cognitive improvement during Tolcapone treatment in Parkinson's disease. Journal of Neural Transmission 104, 887-894.

Gerfen, C.R., Keefe, K.A., Gauda, E.B., 1995. $\mathrm{D}_{1}$ and $\mathrm{D}_{2}$ dopamine receptor function in the striatum: coactivation of $\mathrm{D}_{1^{-}}$and $\mathrm{D}_{2}$-dopamine receptors on separate populations of neurons results in potentiated immediate early gene response in $\mathrm{D}_{1}$-containing neurons. Journal of Neuroscience 15, 8167-8176.

Glickstein, S.B., Hof, P.R., Schmauss, C., 2002. Mice lacking dopamine $\mathrm{D}_{2}$ and $\mathrm{D}_{3}$ receptors have spatial working memory deficits. Journal of Neuroscience 22, 5619-5629.

Glickstein, S.B., Desteno, D.A., Hof, P.R., Schmauss, C., 2005. Mice lacing dopamine $D_{2}$ and $D_{3}$ receptors exhibit differential activation of prefrontal cortical neurons during tasks requiring attention. Cerebral Cortex 15, 1016-1024.

Gogos, J.A., Morgan, M., Luine, V., Santha, M., Ogawa, S., Pfaff, D., Karayiorgou, M., 1998. Catechol- $O$-methyltransferase-deficient mice exhibit sexually dimorphic changes in chatecolamine levels and behavior. Proceedings of the National Academy of Sciences of the United States of America 95, 9991-9996. 
Gopnic, A., Meltzoff, A., Kuhl, P., 1999. The Scientist in the Crib: What Early Learning Tells Us about the Mind. HarperCollins, New York.

Grady, C.L., McIntosh, A.R., Horwitz, B., Maisog, J.M., Ungerleider, L.G., Mentis, M.J., Pietrini, P., Schapiro, M.B., Haxby, J.V., 1995. Age-related reductions in human recognition memory due to impaired encoding. Science 269, 218-221.

Graybiel, A.M., Aosaki, T., Flaherty, A.W., Kimura, M., 1994. The basal ganglia and adaptive motor control. Science 265, 1826-1831.

Graybiel, A.M., 2000. The basal ganglia and adaptive motor control. Current Biology 10, 509-511.

Gruber, W.R., Klimesch, W., Sauseng, P., Doppelmayr, M., 2005. Alpha phase synchronization predicts $\mathrm{P} 1$ and N1 latency and amplitude size. Cerebral Cortex 15, 371-377.

Halliday, R., Naylor, H., Brandeis, D., Callaway, E., Yano, L., Herzig, K., 1994. The effect of D-amphetamine, clonidine, and yohimbine on human information processing. Psychophysiology 31, 331-337.

Hersch, S.M., Ciliax, B.J., Gutekunst, C.A., Rees, H.D., Heilman, C.J., Yung, K.K.L., Bolam, J.P., Ince, E., Yi, H., Levey, A.I., 1995. Electron-microscopic analysis of $\mathrm{D}_{1}$ and $\mathrm{D}_{2}$ dopamine receptor proteins in the dorsal striatum and their synaptic relationships with motor corticostriatal afefrents. Journal of Neuroscience 15, 5222-5237.

Holthoff, V.A., Vieregge, P., Kessler, J., Pietrzyk, U., Herholz, K., Bonner, J., Wagner, R., Wienhard, K., Pawlik, G., Heiss, W.D., 1994. Discordant twins with Parkinson's disease: positron emission tomography and early signs of impaired cognitive circuits. Annals of Neurology 36, 176-182.

Houk, J.C., Davis, J.L., Beiser, D.G. (Eds.), 1995. Models of Information Processing in the Basal Ganglia. MIT Press, Cambridge, MA.

Ichise, M., Ballinger, J.R., Tanaka, F., Moscovitch, M., St. GeorgeHyslop, P.H., Raphael, D., Freedman, M., et al., 1998. Age-related changes in $\mathrm{D}_{2}$ receptor binding with Iodine-123-iodobenzofuran SPECT. Journal of Nuclear Medicine 39, 1511-1518.

Inoue, M., Suhara, T., Sudo, Y., Okubo, Y., Yasuno, F., Kishimoto, T., Yoshikawa, K., Tanada, S., 2001. Age-related reduction of extrastriatal dopamine $\mathrm{D}_{2}$ receptor measured by PET. Life Sciences 69, $1079-1084$.

Jones, G.H., Robbins, T.W., 1992. Differential effects of mesocortical, mesolimbic, and mesostriatal dopamine depletion on spontaneous, conditioned, and drug-induced locomotor activity. Pharmacology, Biochemistry and Behavior 43, 883-895.

Jönsson, E.G., Nothen, M.M., Grunhage, F., Farde, L., Nakashima, Y., Propping, P., Sedvall, G.C., 1999. Polymorphisms in the dopamine $\mathrm{D}_{2}$ receptor gene and their relationships to striatal dopamine receptor density of healthy volunteers. Molecular Psychiatry 4, 290-296.

Joober, R., Gauthier, J., Lal, S., Bloom, D., Lalonde, P., Rouleau, G., Benkelfat, C., Labelle, A., 2002. Catechol- $O$-methyltransferase Val108/158-Met gene variants associated with performance on the Wisconsin Card Sorting Test. Archives of General Psychiatry 59, 662-663.

Joseph, J.A., Denisova, N., Villalobos-Molina, R., 1996. Oxidative stress and age-related neuronal deficits. Molecular and Chemical Neuropathology 28, 35-40.

Joyce, J.N., Sapp, D.W., Marshall, J.F., 1986. Human striatal dopamine receptors are organized in compartments. Proceedings of the National Academy of Sciences 83, 8002-8006.

Kaasinen, V., Vilkman, H., Hietala, J., Nagren, K., Helenius, H., Olsson, H., Farde, L., Rinne, J.O., 2000. Age-related $\mathrm{D}_{2} / \mathrm{D}_{3}$ receptor loss in extrastriatal regions of the human brain. Neurobiology of Aging 21, 683-688.

Kaasinen, V., Kemppainen, N., Nagren, K., Helenius, H., Kurki, T., Rinne, J.O., 2002. Age-related loss of extrastriatal dopamine $\mathrm{D}_{2}$-like receptors in women. Journal of Neurochemistry 81, 1005-1010.

Karoum, F., Chrapusta, S.J., Egan, M.F., 1994. 3-methoxtyramine is the major metabolite of released dopamine in the rat frontal cortex: reassessment of the effects of antipsychotics on the dynamics of dopamine release and metabolism in the frontal cortex, nucleus accumbens, and striatum by a simple two pool model. Journal of Neurochemistry 63, 972-979.
Kausler, D.H., 1991. Experimental Psychology, Cognition, and Human Aging, second ed. Springer, New York.

Kelly, T.H., Foltin, R.W., Fischman, M.W., 1991. The effects of repeated amphetamine exposure on multiple measures of human behavior. Pharmacology, Biochemistry and Behavior 38, 417-426.

Kimberg, D.Y., D'Esposito, M., 2003. Cognitive effects of the dopamine receptor agonist pergolide. Neuropsychologia 41, 1020-1027.

Kimberg, D.Y., D'Esposito, M., Farah, M.J., 1997. Effects of bromocriptine on human subjects depend on working memory capacity. Neuroreport 8, 3581-3585.

Kneavel, M., Gogos, J., Karayiorgou, K., Luine, V., 2000. Interactions of COMT gene deletion and environment on cognition. Society of Neuroscience Abstract 26, 1-2.

Koepp, M.J., Gunn, R.N., Lawrence, A.D., Cunningham, V.J., Dagher, A., Jones, T., Brooks, D.J., Bench, C.J., Grasby, P.M., 1998. Evidence for striatal dopamine release during a video game. Nature 393, 266-268.

Lauritzen, M., 2001. Relationship of spikes, synaptic activity, and local changes of cerebral blood flow. Journal of Cerebral Blood Flow and Metabolism 21, 1367-1383.

Lawrence, A.D., Weeks, R.A., Brooks, D.J., Andrews, T.C., Watkins, L.H.A., Harding, A.E., Robbins, T.W., Sahakian, B.J., 1998. The relationship between dopamine receptor binding and cognitive performance in Huntington's disease. Brain 121, 1343-1355.

Li, S.C., Sikström, S., 2002. Integrative neurocomputational perspectives on cognitive aging, neuromodulation, and representation. Neuroscience and Biobehavioral Reviews 26, 795-808.

Li, S.C., Lindenberger, U., Sikström, S., 2001. Aging cognition: from neuromodulation to representation to cognition. TICS 5, 479-486.

Li, S.C., Lindenberger, U., Hommel, B., Aschersleben, G., Prinz, W., Baltes, P.B., 2004. Lifespan transformations in the couplings of mental abilities and underlying cognitive processes. Psychological Science 15, 155-163.

Li, S.C., Naveh-Benjamin, M., Lindenberger, U., 2005. Aging neuromodulation impairs associative binding: A neurocomputational account. Psychological Science, in press.

Liljequist, R., Haapalinna, A., Ahlander, M., Li, Y.H., Mannisto, P.T., 1997. Catechol- $O$-methyltransferase inhibitor tolcapone has minor influences on performance in experimental memory models in rats. Behavioural Brain Research 82, 195-202.

Logothetis, N.K., Pauls, J., Augath, M., Trinath, T., Oeltermann, A., 2001. Neurophysiological investigation of the basis of the fMRI signal. Nature 412, 150-157.

Lotta, T., Vidgren, J., Tilgmann, C., Ulmanen, I., Melen, K., Julkunen, I., Taskinen, J., 1995. Kinetics of human soluble and membrane-bound catechol- $O$-methyltransferase: a revised mechanism and description of the termolabile variant of the enzyme. Biochemistry 34, 4202-4210.

Lövdén, M., Lindenberger, U. Development of intellectual abilities in old age: From age gradients to individuals. In: Wilhelm, O., Engle, R.W. (Eds.), Handbook of Understanding and Measuring Intelligence. Sage, Thousand Oaks, CA, pp. 203-221.

Luciana, M., Collins, P.F., 1997. Dopamine modulates working memory for spatial but not object cues in normal humans. Journal of Cognitive Neuroscience 9, 330-347.

Luciana, M., Depue, R.A., Arbisi, P., Leon, A., 1992. Facilitation of working memory in humans by a $\mathrm{D}_{2}$ dopamine receptor agonist. Journal of Cognitive Neuroscience 4, 58-68.

Luciana, M., Collins, P.F., Depue, R.A., 1998. Opposing roles for dopamine and serotonin in the modulation of human spatial working memory functions. Cerebral Cortex 8, 218-226.

Luo, Y., Roth, G.S., 2000. The roles of dopamine oxidative stress and dopamine receptor signaling in aging and age-related neurodegeneration. Antioxidants \& Redox Signaling 2, 449-460.

Ma, S.Y., Ciliax, B.J., Stebbins, G., Jaffar, S., Joyce, J.N., Cochran, E.J., Kordower, J.H., Mash, D.C., Levey, A.I., Mufson, E.J., 1999. Dopamine transporter-immunoreactive neurons decrease with age in the human substantia nigra. Journal of Comparative Neurology 409, 25-37. 
MacDonald, S.W.S., Hultsch, D.F., Dixon, R.A., 2003. Performance variability is related to change in cognition: evidence from the Victoria Longitudinal Study. Psychology and Aging 18, 510-523.

Makeig, S., Debener, S., Onton, J., Delorme, A., 2004. Mining eventrelated brain dynamcis. Trends in Cognitive Neuroscience 8, 204-210.

Malhotra, A.K., Kestler, L.J., Mazzanti, C., Bates, J.A., Goldberg, T., Goldman, D., 2002. A functional polymorphism in the COMT gene and performance on a test of prefrontal cognition. American Journal of Psychiatry 159, 652-654.

Mannisto, P.T., Kaakkola, S., 1999. Catechol- $O$-methyltransferase (COMT): biochemistry, molecular biology, and clinical efficacy of the new selective COMT inhibitors. Pharmacological Reviews 51, 593-628.

Mäntylä, T., Bäckman, L., 1992. Aging and memory for expected and unexpected objects in real-world settings. Journal of Experimental Psychology—Learning Memory Cognition 18, 1298-1309.

Mattay, V.S., Goldberg, T.E., Fara, F., Hariri, A.R., Tessitore, A., Egan, M.F., Kolachana, B., Callicott, J.H., Weinberger, D.R., 2003. Catechol $O$-methyltransferase val $^{158}$-met genotype and individual variation in the brain response to amphetamine. Proceedings of the National Academy of Sciences of the United States of America 100, 6186-6191.

McEntee, W.J., Mair, R.G., Langlais, P.J., 1987. Neurochemical specificity of learning: dopamine and motor learning. Yale Journal of Biology and Medicine 60, 187-193.

Mehta, M.A., Owen, A.M., Sahaikan, B.J., Mavaddat, N., Pickard, J.D., Robbins, T.W., 2000. Methylphenidate enhances working memory by modulating discrete frontal and parietal lobe regions in the human brain. Journal of Neuroscience 20, RC 65.

Mesco, E.R., Carlsson, S.G., Joseph, J.A., Roth, G.S., 1993. Decreased striatal $\mathrm{D}_{2}$ dopamine receptor mRNA synthesis during aging. Molecular Brain Research 17, 160-162.

Morgan, D.G., Finch, C.E., 1998. Dopaminergic changes in the basal ganglia: a generalized phenomenon of aging in mammals. Annals of the New York Academy of Sciences 515, 145-160.

Mozley, P.D., Acton, P.D., Barraclough, E.D., Plossl, K., Gur, R.C., Alavi, A., Mathur, A., Saffer, J., Kung, H.F., 1999. Effects of age on dopamine transporters in healthy humans. Journal of Nuclear Medicine 40, 1812-1817.

Mozley, L.H., Gur, R.C., Mozley, P.D., Gur, R.E., 2001. Striatal dopamine transporters and cognitive functioning in healthy men and women. American Journal of Psychiatry 158, 1492-1499.

Müller, U., Wächter, T., Barthel, H., Reuter, M., von Cramon, D.Y., 2000. Striatal $\left[{ }^{123} \mathrm{I}\right] \beta$-CIT SPECT and prefrontal cognitive functions in Parkinson's disease. Journal of Neural Transmission 107, 303-319.

Nordström, A.L., Farde, L., Pauli, S., Litton, J.E., Halldin, C., 1992. PET analysis of $\left[{ }^{11} \mathrm{C}\right]$ raclopride binding in healthy young adults and schizophrenic patients: reliability and age effects. Human Psychopharmacology 7, 157-165.

Oades, R.D., 1985. The role of noradrenaline in tuning and dopamine in switching between signals in the CNS. Neuroscience and Biobehavioral Reviews 9, 261-282.

Olesen, P.J., Westerberg, H., Klingberg, T., 2004. Increased prefrontal and parietal activity after training of working memory. Nature Neuroscience 7, 75-79.

Ouchi, Y., Yoshikawa, E., Futatsubashi, M., Okada, H., Torizuka, T., Sakamoto, M., 2002. Effect of simple motor performance on regional dopamine release in the striatum in Parkinson disease patients and healthy subjects: a positron emission tomography study. Journal of Cerebral Blood Flow and Metabolism 22, 746-752.

Pappata, S., Deheane, J.B., Poline, M.C., Gregoire, M.C., Jobert, A., Delforge, J., Frouin, V., Bottlaender, M., Dolle, F., Di Giamberardino, L., Syrota, A., 2002. In vivo detection of striatal dopamine release during reward: a PET study with $\left[{ }^{11} \mathrm{C}\right]$ raclopride and a single dynamic scan approach. Neuroimage 16, 1015-1027.

Parent, A., Hazrati, L.N., 1995. Functional anatomy of the basal ganglia. I. The cortico-basal ganglia-thalamo-cortical loop. Brain Research Reviews 20, 91-127.
Park, D.C., 2000. The basic mechanisms accounting for age-related decline in cognitive function. In: Park, D.C., Schwarz, N. (Eds.), Cognitive Aging: A Primer. Psychology Press, Philadelphia, pp. 3-18.

Park, D.C., Lautenschlager, G., Hedden, T., Davidson, N.S., Smith, A.D., Smith, P.K., 2002. Models of visuospatial and verbal memory across the adult life span. Psychology and Aging 17, 299-320.

Pasupathy, A., Miller, E.A., 2005. Different time courses of learningrelated activity in the prefrontal cortex and striatum. Nature 433, 873-876.

Prull, M.W., Gabrieli, J.D.E., Bunge, S.A., 1999. Age-related changes in memory: a cognitive neuroscience perspective. In: Craik, F.I.M., Salthouse, T.A. (Eds.), Handbook of Aging and Cognition, vol. 2. Erlbaum, Mahwah, NJ, pp. 91-153.

Ramaekers, J.G., Louwerens, J.W., Muntjewerff, N.D., Milius, H., de Bie, A., Rosenzweig, P., Patat, A., O'Hanlon, J.F., 1999. Psychomotor, cognitive, extrapyramidal and affective functions of healthy volunteers during treatment with an atypical (amisulpiride) and a classic (haloperidol) antipsychotic. Journal of Clinical Psychopharmacology 19, 209-221.

Reeves, S., Bench, C., Howard, R., 2002. Aging and the nigrostriatal dopamine system. International Journal of Geriatric Psychiatry 17, 359-370.

Rinne, J.O., Lönnberg, P., Marjamäki, P., 1990. Age-dependent decline of dopamine- $\mathrm{D}_{1}$ and dopamine- $\mathrm{D}_{2}$ receptor. Brain Research 508, 349-352.

Rinne, J.O., Sahlberg, N., Ruottinen, H., Nagren, K., Lehikoinen, P., 1998. Striatal uptake of the dopamine reuptake ligand $\left[{ }^{11} \mathrm{C}\right] \beta$-CFT is reduced in Alzheimer's disease assessed by positron emission tomography. Neurology 50, 152-156.

Roberts, A.C., De Salvia, M.A., Wilkinson, L.S., Collins, P., Muir, J.L., Everitt, B.J., Robbins, T.W., 1994. 6-hydroxydopamine lesions of the prefrontal cortex in monkeys enhance performance on an analog of the Wisconsin card sort test: possible interactions with subcortical dopamine. Journal of Neuroscience 14, 2531-2544.

Rönnlund, M., Nyberg, L., Bäckman, L., Nilsson, L.G., 2005. Stability, improvement, and decline in adult life-span development of declarative memory: cross-sectional and longitudinal data from a populationbased study. Psychology and Aging 20, 3-18.

Rypma, B., D'Esposito, M., 2000. Isolating the neural mechanisms of agerelated changes in human working memory. Nature Neuroscience 3, 509-515.

Rypma, B., Prabhakaran, V., Desmond, J.D., Gabrieli, J.D.E., 2001. Age differences in prefrontal cortical activity in working memory. Psychology and Aging 16, 371-384.

Sakata, M., Farooqui, S.M., Prasad, C., 1992. Post-transcriptional regulation of loss of rat striatal $\mathrm{D}_{2}$ dopamine receptor during aging. Brain Research 575, 309-314.

Salthouse, T.A., 1992. Reasoning and spatial abilities. In: Craik, F.I.M., Salthouse, T.A. (Eds.), Handbook of Aging and Cognition. Erlbaum, Hillsdale, NJ, pp. 167-211.

Sawaguchi, T., Goldman-Rakic, P.S., 1991. $\mathrm{D}_{1}$ dopamine receptors in prefrontal cortex: involvement in working memory. Science 251, 947-950.

Sawaguchi, T., Matsamura, M., Kubota, K., 1988. Dopamine enhances the neuronal activity of spatial short-term memory in the primate prefrontal cortex. Neuroscience Research 5, 465-473.

Schultz, W., 2002. Getting formal with dopamine and reward. Neuron 36, 241-263.

Seamans, J.K., Yang, C.R., 2004. The principal features and mechanisms of dopamine modulation in the prefrontal cortex. Progress in Neurobiology 74, 1-57.

Seeman, P., Bzowej, N.H., Guan, H.C., Bergeron, C., Becker, L.E., Reynolds, G.P., Bird, E.D., Riederer, P., Jellinger, K., Watanabe, S., Tourtellotte, W.W., 1987. Human brain dopamine receptors in children and aging adults. Synapse 1, 399-404.

Servan-Schreiber, D., Bruno, R.M., Carter, C.S., Cohen, J.D., 1998a. Dopamine and the mechanisms of cognition: part I. A neural network model predicting dopamine effects on selective attention. Biological Psychiatry 43, 713-722. 
Servan-Schreiber, D., Carter, C.S., Bruno, R.M., Cohen, J.D., 1998b Dopamine and the mechanisms of cognition: part II. D-amphetamine effects in human subjects performing a selective attention task. Biological Psychiatry 43, 723-729.

Severson, J.A., Marcusson, J., Winblad, B., Finch, C.E., 1982. Agecorrelated loss of dopaminergic binding sites in human basal ganglia. Journal of Neurochemistry 39, 1623-1631.

Shinkai, T., Zhang, L., Mathias, S.A., Roth, G.S., 1997. Dopamine induces apoptosis in cultured rat striatal neurons: possible mechanism of $\mathrm{D}_{2}$-dopamine receptor neuron loss during aging. Journal of Neuroscience Research 47, 393-399.

Simon, H., Taghzouti, K., Le Moal, M., 1986. Deficits in spatial-memory tasks following lesions of septal dopaminergic terminals in the rat. Behavioural Brain Research 19, 7-16.

Singer, W., Gray, C.M., 1995. Visual feature integration and the temporal correlation hypothesis. Annual Review of Neuroscience 18, 555-586.

Snow, B.J., Tooyama, I., McGeer, E.G., Yamada, T., Calne, D.B., Takahashi, H., Kimura, H., 1993. Human positron emission tomographic $[18 \mathrm{~F}]$ fluorodopa studies correlate with dopamine cell counts and levels. Annals of Neurology 34, 324-330.

Spiegel, R., 1978. Effects of amphetamines on performance and on polygraphic sleep parameters in man. Advances in Biosciences 21, 189-201.

Stebbins, G.T., Carrillo, M.C., Dorfman, J., Dirksen, C., Desmond, J.E., Turner, D.A., Bennett, D.A., Wilson, R.S., Glover, G., Gabrieli, J.D.E., 2002. Aging effects on memory encoding in the frontal lobes. Psychology and Aging 17, 44-55.

Suhara, T., Fukuda, H., Inoue, O., Itoh, T., Suzuki, K., Yamasaki, T., Tateno, Y., 1991. Age-related changes in human $D_{1}$ dopamine receptors measured by positron emission tomography. Psychopharmacology 103, 41-45.

Van Dyck, C.H., Seibyl, J.P., Malison, R.T., Laurelle, M., Wallace, E., Zoghbi, S.S., Zeaponce, Y., Baldwin, R.M., Charney, D.S., Hoffer, P.B., Innis, R.B., 1995. Age-related decline in striatal dopamine transporter binding with iodine-123- $\beta$-CIT. Journal of Nuclear Medicine 36, 1175-1181

Volkow, N.D., Wang, G.J., Fowler, J.S., Ding, Y.S., Gur, R.C., Gatley, J., Logan, J., Moberg, P.J., Hitzemann, R., Smith, G., Pappas, N., 1998a. Parallel loss of presynaptic and postsynaptic dopamine markers in normal aging. Annals of Neurology 44, 143-147.
Volkow, N.D., Gur, R.C., Wang, G.J., Fowler, J.S., Moberg, P.J., Ding, Y.S., Hitzemann, R., Smith, G., Logan, J., 1998b. Association between decline in brain dopamine activity with age and cognitive and motor impairment in healthy individuals. American Journal of Psychiatry 155, 344-349.

Volkow, N.D., Logan, J., Fowler, J.S., Wang, G.J., Gur, R.C., Wong, C., Felder, C., Gatley, S.J., Ding, Y.S., Hitzemann, R., Pappas, N., 2000. Association between age-related decline in brain dopamine activity and impairment in frontal and cingulate metabolism. American Journal of Psychiatry $157,75-80$.

von der Malsburg, C., 1985. Nervous structures with dynamical links. Berichte der Bunsengesellschaft fuer Physikalische Chemie 89, 703-710.

Wang, Y., Chan, G.L.Y., Holden, J.E., Dobko, T., Mak, E., Schulzer, M., Huser, J.M., Snow, B.J., Ruth, T.J., Calne, D.B., Stoessl, A.J., 1998. Age-dependent decline of dopamine $\mathrm{D}_{1}$ receptors in human brain: a PET study. Synapse 30, 56-61.

Wang, M., Vijayraghavan, S., Goldman-Rakic, P.S., 2004. Selective $\mathrm{D}_{2}$ receptor actions on the functional circuitry of working memory. Science 303, 853-856.

Weinshilboum, R.M., Otterness, D.M., Szumlanski, C.L., 1999. Methylation pharmacogenetics: catechol- $O$-methyltransferase, thiopurine methyltransferase, and histamine $N$-methyltransferase. Annual Review of Pharmacology and Toxicology 39, 19-52.

West, R.L., 1996. An application of prefrontal cortex function theory to cognitive aging. Psychological Bulletin 120, 272-292.

Williams, G.V., Goldman-Rakic, P.S., 1995. Modulation of memory fields by dopamine $\mathrm{D}_{1}$ receptors in prefrontal cortex. Nature 376, 572-575.

Winterer, G., Coppola, R., Goldberg, T.E., Egan, M.F., Jones, D.W., Sanchez, C.E., Weinberger, D.R., 2004. Prefrontal broadband noise, working memory, and genetic risk for schizophrenia. American Journal of Psychiatry 161, 490-500.

Yang, Y.K., Chiu, N.T., Chen, C.C., Chen, M., Yeh, T.L., Lee, I.H., 2003. Correlation between fine motor activity and striatal dopamine $\mathrm{D}_{2}$ receptor density in patients with schizophrenia and healthy controls. Psychiatry Research Neuroimaging 123, 191-197.

Zhang, L., Ravipati, A., Joseph, J., Roth, G.S., 1995. Aging-related changes in rat striatal $\mathrm{D}_{2}$ dopamine receptor mRNA-containing neurons: a quantitative nonradioactive in situ hybridization study. Journal of Neuroscience 15, 1735-1740. 